PNL- -8222

DE93 002862

\title{
AN ASSESSMENT OF ALTERNATIVES AND TECHNOLOGIES FOR REPLACING OZONE-DEPLETING SUBSTANCES \\ AT DOE FACILITIES
}
C.W. Purcell
K.B. Miller
J.R. Friedman
R.D. Rapoport
D.R. Conover
P.L. Hendrickson
T.C. Koss

October 1992

Prepared for the U.S. Department of Energy, Office of Environmental Guidance under Contract DE-ACO6-76RLO 1830

Pacific Northwest Laboratory

Richland, Washington 99352

(a) U.S. Department of Energy, Office of Environmental Guidance

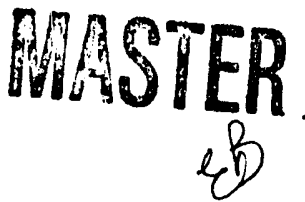




\section{EXECUTIVE SUMMARY}

Title VI of the Clean Air Act, as amended, mandates a production phaseout for ozone-depleting substances (ODSs). In February 1992, President Bush accelerated the phase-out schedule for the most damaging ODSs. These requirements will have a significant impact on U.S. Department of Energy (DOE) facilities.

Currently, DOE uses ODSs in three major activities: fire suppression (halon), refrigeration and cooling (chlorofluorocarbons [CFCs]), and cleaning that requires solvents (CFCs, methyl chloroform, and carbon tetrachloride). For all these activities, interim phase-out measures include substituting chemicals less damaging to the ozone layer, and conserving and recycling ODSs. Specific strategies and alternatives for ultimate ODS phase-out include process changes and non-ODS chemical substitutes.

This report provides basic information on methods and strategies to phase out use of ODSs at DOE facilities. This information is based on preliminary data provided by DOE on the amounts and types of ODSs used by DOE and on discussions with personnel at several DOE facilities. Because decisions on safe alternatives have yet to be made by the U.S. Environmental Protection Agency (EPA) and determination of the most appropriate alternatives will need to be made on a site-specific basis, no alternatives are recommended in this report. The information provided was gathered from the latest United Nations Environment Programme (UNEP) reports, information on current industry activities, information on ODS use at DOE facilities, and reports from national and international ozone protection organizations. 


\section{ACRONYMS}

AFFF
CFC
CO
DOD
DOE
EPA
GDP
HCFC
HFC
MAC
Mi1 $=$ Standards
MILSPECS
ODP
ODS
PFC
PNL
SAE
SCF
SNAP
UL
UNEP
UV
VOC

Aqueous Film Forming Foam

Clilorofluorocarbon

Carbon Dioxide

U.S. Department of Defense

U.S. Department of Energy

U.S. Environmental Protection Agency

Gaseous Diffusion Plant

Hydrochlorofluorocarbon

Hydrofluorociarbon

Mobile Air Conditioner

Military Standards

Military Specifications

Ozone Depletion Potential

Ozone-Depleting Substance

Perfluorocarbon

Pacific Northwest Laboratory

Society of Automotive Engineers

Supercritical Fluid

Significant New Alternatives Policy

Underwriters Laboratory

United Nations Environment Programne ultraviolet

Volatile Organic Compound 


\section{GLOSSARY OF TERMS}

Al iphatic Hydrocarbons

Azeotrope

Clean Agent

Nonazeotrope

Perfluorocarbon

Surfactant

Ternary Blend

Terpene
Organic hydrocarbons having an open chain structure and consisting of paraffin, olefin, and acetylene hydrocarbons and their derivatives.

A mixture of chemicals that, when combined in certain proportions, will distill at a rate which maintains those proportions. Azeotropic mixtures have different vapor pressures than a single constituent and thus exhibit a change in boiling and freezing points. These are important in chiller and compressor design.

An extinguishing agent of commercial quality (virgin) that leaves no detrimental residue. (theoretical)

Blends comprising multiple components of different volatiles that, when used in refrigeration cycles, change volumetric composition and saturation temperatures as they evaporate or condense at constant pressure.

A compound of fluorine and carbon where all the hydrogen atoms are replaced by fluorine atoms. The chemical inertness of perfluorocarbons make them useful as solvents, lubricants, and insulators.

A chemical, generally a detergent, used to reduce the surface tension of water.

A mixture of three chemicals combined in a manner to match a specific boiling point. The current, most promising (to replace CFC-12) is a mixture of HCFC-22, HCFC-124, and HFC-152a that exhibits similar thermodynamic properties as CFC-12 and has an ODP of 0.03 .

A homocyclic hydrocarbon with the empirical formula $\mathrm{C}_{10} \mathrm{H}_{16}$. 


\section{CONTENTS}

EXECUTIVE SUMMARY ...................... i ii

ACRONYMS ....................... v

GLOSSARY OF TERMS .................... vi

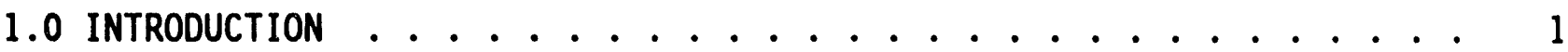

2.0 DOE USES OF OZONE-DEPLETING SUBSTANCES (ODSS) AND POTENTIAL SUBSTITUTES ...

2.1 USE OF HALONS IN FIRE SUPPRESSION .......... 6

2.1 .1 CHANGES IN PROCESSES TO REDUCE HALON USE . . . . . . 9

2.1 .2 CHEMICAL SUBSTITUI IS FOR HALON . . . . . . . . . 13

2.1 .3 CONSERVATION OF HALON . . . . . . . . . . 17

2.2 USE OF CFCS IN REFRIGERATION AND AIR CONDITIONING $\cdots . . .17$

2.2.1 COMFORT COOLING ............... 18

2.2.2 REFRIGERANT APPLICATIONS . . . . . . . . 18

2.2.3 ALTERNATIVES FOR REDUCING CFC USE IN REFRIGERATION AND AIR CONDITIONING ............ 19

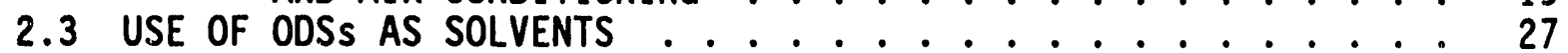

2.3 .1 ELECTRONICS . . . . . . . . . . . 28

2.3 .2 PRECISION CLEANING ............. 29

2.3.3 METAL CLEANING . . . . . . . . . . . . . 29

2.3.4 ALTERNATIVES FOR REDUCING ODSS IN SOLVENT USE ... 30

2.4 SOLVENTS USED TO CLEAN EQUIPMENT CONTAMINATED WITH

RADIOACTIVE DUSTS ................ 38

3.0 OVERVIEW OF CURRENT DOE ACTIVITIES TO PHASE OUT ODSS ........ 41

3.1 FIRE SUPPRESSION .................. 41

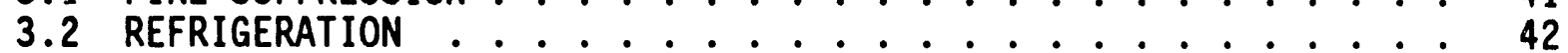

3.3 SOLVENTS ...................... 43

REFERENCES .................... 47

APPENDIX A - POSSIBLE ALTERNATIVES CONSIDERED FOR REVIEW UNDER THE

SIGNIFICANT NEW ALTERNATIVES POLICY (SNAP) PROGRAM . . . . . . . 49

APPENDIX B - SELECTED CONTACTS . . . . . . . . . . . . 49 


\section{FIGURES}

2.1a Portable Fire Suppression Use Evaluation Matrix . . . . . . . . 10

2.1b Fixed Fire Suppression System Use Evaluation Matrix . . . . . . . 11

2.2 Compressor Type vs. Capacity vs. Refrigerant . . . . . . . . 20

2.3 EPA-Approved Recycle Systems for Mobile Air Conditioning . . . . 23

2.4 Alternatives for ODS Solvents ................ 31

\section{TABLES}

1.0 List of Class I and Class II Substances ........... 2 


\subsection{INTRODUCTION}

Title VI of the Clean Air Act, as amended, has many new provisions for protecting the stratospheric ozone layer, including phase-out dates for production of ozone-depleting substances (ODSs). On February 11, 1992, prompted by data from the National Aeronautics and Space Administration indicating that the ozone layer was beirg eroded at a faster rate than originally believed, President Bush announced a four-year acceleration (to December 31,1995 ) in the production phase-out for the most significant (Class I) ODSs. A list of Class I and Class II substances is shown in Table 1. Class I substances include halons, chlorofluorocarbons (CFCs), methyl chloroform, and carbon tetrachloride. Hydrochlorofluorcarbons (HCFCs) are classified as Class II substances. Because the phase-out and other requirements of Title VI will have a broad impact on DOE operations, the DOE Office of Environmental Guidance (EH-23) determined that information on alternatives to these substances needed to be disseminated throughout the Department.

Some of the information used for this report was provided by EH-23. EH23 collected preliminary information from DOE facilities on uses, purchases, inventories, and emissions of ODSs. Facilities were also requested to indicate whether they had sperific plans in place for phasing out ODS use and to describe activities they are undertaking toward this goal. This information was used to compile a database of current DOE ODS use. Information in the database is grouped into three broad categories: refrigeration and air conditioning, fire suppression, and solvents.

This report provides current information on alternative processes and chemical substitutes that have been identified for each of these broad categories. Because of the rapid advancement of the technology, industry will likely develop additional substitutes and new alternative processes. This report is intended to provide information on the major uses of ODSs at DOE facilities, to identify potential alternatives to these uses, and to provide some information on the types of phase-out activities currently being undertaken at specific facilities. Decisions on which options will work best in a given application will. need to be made on a case-by-case basis by each 
Table 1

List of Class I and Class II Substances

From the Clean Air Act Amendments of $1990^{\circ}$

chlorofluorocarbon-11 (CFC-11)

chlorofluorocarbon-12 (CFC-12)

chlorofluorocarbon-113 (CFC-113)

chlorofluorocarbon-114 (CFC-114)

chlorofluorocarbon-115 (CFC-115)

halon-1211

halon-1301

halon-2402

\section{Class I Substances}

chlorofluorocarbon-13 (CFC-13)

chlorofluorocarbon-111 (CFC-111)

shlorofluorocarbon-112 (CFC-112)

chlorofiuorocarbon-211 (CFC-211)

chlorofluorocarbon-212 (CFC-212)

chlorofluorocarbon-213 (CFC-213)

chlorofluorocarbon-214 (CFC-214)

chlorofluorocarbon-215 (CFC-215)

chlorofluorocarbon-216 (CFC-216)

chlorofluorocarbon-217 (CFC-217)

carbon tetrachloride

methyl chloroform

\section{Class II Substances}

hydrochlorofluorocarbon-21 (HCFC-21) hydrochlorofluorocarbon-22 (HCFC-22) hydrochlorofluorocarbon-31 (HCFC-31) hydrochlorofluorocarbon-121 (HCFC-121) hydrochlorofluorocarbon-122 (HCFC-122) hydrochlorofluorocarbon-123 (HCFC-123) hydrochlorofluorocarbon-124 (HCFC-124) hydrochlorofluorocarbon-131 (HCFC-131) hydrochlorofluorocarbon-132 (HCFC-132) hydrochlorofluorocarbon-133 (HCFC-133) hydrochlorofluorocarbon-141 (HCFC-141) hydrochlorofluorocarbon-142 (HCFC-142) hydrochlorofluorocarbon-221 (HCFC-221) hydrochlorofluorocarbon-222 (HCFC-222) hydrochlorofluorocarbon-223 (HCFC-223) hydrochlorofluorocarbon-224 (HCFC-224) hydrochlorofluorocarbon-225 (HCFC-225) hydrochlorofluorocarbon-226 (HCFC-226) hydrochlorofluorocarbon-231 (HCFC-231) hydrochlorofluorocarbon-232 (HCFC-232) hydrochlorofluorocarbon-233 (HCFC-233) hydrochlorofluorocarbon-234 (HCFC-234) hydrochlorofluorocarbon-235 (HCFC-235) hydrochlorofluorocarbon-241 (HCFC-241) hydrochlorofluorocarbon-242 (HCFC-242) hydrochlorofluorocarbon-243 (HCFC-243) hydrochlorofluorocarbon-244 (HCFC-244) hydrochlorofluorocarbon-251 (HCFC-251) hydrochlorofluorocarbon-252 (HCFC-252) hydrochlorofluorocarbon-253 (HCFC-253) hydrochlorofluorocarbon-261 (HCFC-261) hydrochlorofluorocarbon-262 (HCFC-262) hydrochlorofluorocarbon-271 (HCFC-271)

a

In general. a molecule's ozone depletion potential (ODP) decreases as more hydrogen atoms replace halogen atom (i.e.. chlorine or bromine). Class II substances are generally considered safer than Class I substances because they contain fewer halogen atoms and therefore have shorter atmospheric lifetimes. 
facility. For this reason, this report does not recommend specific alternatives or options. Recycle/reuse and minimization options have been recommended as ways to reduce unnecessary releases of ODSs until such time as the ODSs can be replaced.

Section 2 of this report gives a brief overview of DOE ODS use by broad category and discusses potential alternatives (both chemical substitutes and process changes) to these uses. Section 3 summarizes activities that particular DOE facilities currently are undertaking to phase out ODSs. Section 4 provides conclusions. 


\subsection{DOE USES OF OZONE-DEPLETING SUBSTANCES (ODSS) AND POTENTIAL SUBSTITUTES}

The information in this report is based on preliminary data collected by EH-23 on uses of ODSs at DOE facilities. Because of the preliminary nature of these data, this information should be used only as a general reference for the amounts and types of ODSs used by DOE.

Approximately 90 percent of the total DOE reported ODS stock (in-system and reserve) inventories consisted solely of CFC-114, the coolant used in the three current and former Gaseous Diffusion Plants (GDP). The GDP complex is well organized in its approach to ozone protection issues and has an active CFC-114 Replacement Task Force. Because the task force has comprehensive plans in place to replace CFC-114, GDP replacement activities will not be discussed further in this report.

Other ODS species used in quantity at DOE facilities are CFC-11, CFC-12, and HCFC-22 for refrigeration and air conditioning; Halon-1211 and Halon-1301 for fire protection; and CFC-113, carbon tetrachloride, and methyl chloroform for solvent use. ODS emissions from solvent usage account for about one-third of DOE's total ODS releases, and ODS emissions from refrigeration and air conditioning are about 10 percent of the total, according to preliminary information compiled by EH-23.

This section discusses potential alternatives for ODSs in major DOE use categories. It is divided into the following broad subject categories: fire protection/suppression, refrigeration and air conditioning, and solvents. DOE-specific uses are addressed, where applicable, under each of these sections. Appendix A consists of a table of alternative technologies and chemical substitutes being considered for review by EPA under the Significant New Alternatives Policy (SNAP) Program, EPA's program for evaluating safe alternatives, as required by Section 612 of the Clean Air Act, as amended. 


\subsection{USE OF HALONS IN FIRE SUPPRESSION ${ }^{(a)}$}

Fire protection is accomplished throughout DOE facilities by using standard, accepted technologies approved by the National Fire Protection Association and the Factory Mutual best practices guidelines. Until recently, the widespread use of halons in both fixed and portable systems was an accepted practice. Current DOE policy, as reflected in a memorandum dated September 27, 1990 ("Interim Position on Installation of New Halon-1301 Fixed Fire Suppression Systems and Halon Portable Fire Extinguishers"), discourages the use of halons in fixed and portable fire suppression. This policy states that no new halon fire suppression systems can be proposed and no new halon portable fire extinguishers can be purchased. Existing halon systems are to be maintained, pending determination of a DOE position on CFCS and halons.

Halons are brominated chlorofluorocarbon compounds uniquely able to arrest combustion in the earliest stages of a fire. Halon-1211 and Halon-1301 are very effective, have very low toxicity and do not leave a residue or cause corrosion. They are nonconductive and will not cause damage to energized electrical equipment due to short circuits. Halon-1301, a gas at standard temperature and pressure, is used primarily in "total flooding" applications in automatic fire-suppression systems. It is also nontoxic under normal conditions, does not displace oxygen, and is sare to use in occupied areas. Halon-1211, a liquid at standard temperature and pressure, is used primarily in portable systems as a streaming agent, i.e., it is dispersed from a fire extinguisher directly on the fire. Halon 1211 also has very low toxicity, is clean, nonconductive and noncorrosive.

A complete halon fire suppression system typically will rely on a network of automatic sensor devices capable of detecting heat, flame, smoke, combustible vapors or an abnormal condition that is likely to produce fire; these devices are wired to a control panel. When the detectors are activated, the control panel activates audible and visual alarms, institutes a preset countdown sequence, interrupts electrical power and air flow to the area, and discharges the fire suppression agent. The current National Fire Protection

\footnotetext{
(a) The term "system" is generally used in this section to describe a fixed fire suppression system, while
} "extinguisher(s)" refers to portable fire extinguishers. 
Association Standard $12 \mathrm{~A}$ calls for total flooding of the space within 10 seconds, at a concentration of five percent Halon-1301 by volume (NFPA 1989).

Halon-1301 is used in fixed fire suppression systems throughout most of the DOE complex. These systems have been installed to provide a very high level of property protection with minimal secondary damage. Haloir-1301 total flooding systems can prevent explosions and extinguish fires quickly. Because of this, they can prevent the spread of fire to surrounding areas and limit escalation of fire emergencies. This has a direct, positive impact on personnel safety. Kalon protection systems are usually installed in areas that contain sensitive electrical equipment, such as computers, because halons are not electrically conductive and will not contribute to electrical short circuits. The Halon-1301 systems are also used in areas that process or store fissile materials.

The need to use halons in fixed fire suppression systems is based on the type of equipment and property to be protected. Some systems currently using halons could be replaced by other, effective fire suppression methods;

however, alternative systems may also be more costly in terms of the amount of damage done by both the fire and the suppression method. Also, some situations do not have adequate fire protection alternatives. In cases where a high risk of explosion or severe fire damage exists, halon use may qual ify for an exemption under the Clean Air Act, as amended (Section 604(f) and (g)). This narrow exemption could provide halons in limited quantities after the production phase-out date but will also make these substances correspondingly more expensive. According to the 1991 report by the Halons Technical Options Committee of the United Nations Environment Programme (UNEP) ${ }^{(a)}$, the following criteria should be considered to determine whether it is essential to use halons:

- A critical need must exist to minimize damage due to fire, explosions or extinguishing agent application, which would otherwise result in serious impairment of an essential service to society, or pose an unacceptabie threat to life, the environment, or national security. and

(a) UNEP is developing recommendations for adjustments and amendments to the Montreal Protocol and has examined the essential use issue. Implenentations of exemptions in the Clean Air Act. as amended, must be consistent with the Montreal Protocol. 
- All other appropriate fire protection measures have been taken (UNEP 1991a).

Currently, the Montreal Protocol recognizes that there are fire/explosion risk scenarios for which current fire protection technology cannot provide adequate protection without the use of halons; however, there are no established definitions of a specific essential use. It may be necessary to have the Protocol signatories establish an "essential use list" or mechanism to allow a nation to define its essential uses. If this is not accomplished, a nation could be considered out of compliance and suffer the consequences.

Several options are currently available for replacing halons in fixed and portable fire suppression systems. The alternative choices may not provide the same level of protection as halons and in certain circialtances could result in greater fire loss and risk to personnel and equipment. These risks must be carefully compared with the environmertal risk associated with the continued use of halons. As a guide, the UNEP Halons Technical Opitions Committee has developed use evaluation matrices to logically evaluate alternative fire protection systems. These evaluations do not specifically consider the unique requirements posed by each site, but they do compare the important attributes of the fire suppression alternatives. Attributes of a particular alternative, such as the ability to extinguish flammable liquids, may be more important in some applications (e.g., flammable liquid stores) than in others (e.g., computer rooms).

Each fire suppression alternative addressed in the matrices has specific properties that have advantages and disadvantages depending on the application in which the alternative is used. The following parameters were used for comparison in the evaluation matrices:

1. Low Space or Meight Requirements - weight-based effectiveness of the agent/system against a zero ODP clean agent.

2. Damage Limiting Capability - the relative level of direct and secondary fire damage expected for a similar fire suppression system. It is also a measure of the response time of the system and the downtime of equipment not directly damaged by the fire. 
3. Ability to Permeate - the ability of the agent to be effective in obstructed geometry situations where it cannot be directly applied to the burning surface. This property is especially important in sub-floor areas and electronics cabinets.

4. Occupant Risk - the toxicity of the undecomposed agent in concentrations necessary for extinguishing.

5. Flammable Liquid Extinguishing Capability - the ability of the agent and application method to extinguish liquid fuel fires in two dimensions and liquid and gas phase fuel fires in three dimensions.

6. Efficacy - the effectiveness and reliability of the system in a particular application.

7. Nonconductivity - the ability to be applied to energized electrical equipment without causing shorts and damage and without posing a safety risk to nearby occupants.

8. Cost - of installation and maintenance.

An additional parameter is used in evaluating portable extinguishers:

9. Stream Range - the ability of the agent to maintain a coherent effective stream over a modest distance.

The assessment of alternatives to halons in Figures $2.1 \mathrm{a}$ and $2.1 \mathrm{~b}$ is based primarily on the methods and matrices developed by the UNEP's Halons Technical eptions Committee. The total score is the sum of the individual scores for each of the alternatives. Although individual issues, such as electrical conductivity, must be assessed on a case-by-case basis to determine the applicability of the alternative, alternatives with higher total scores are thos: that had the best performance overall.

\subsubsection{CHANGES IN PROCESSES TO REDUCE HALON USE}

A reasonable approach to the phase-out of halons is the use of non-haion fire suppression systems. In many situations, non-halon suppression systems may be viable for protecting resources. The following descriptions briefly cover some potential alternatives to halons. These options are presented as possible halon system replacements in the UNEP Halon Technical Options Committee 1991 report and are representative of the possible systems that could be used in selected applications. Before changing the type of fire protection system being used, it is vital that a knowledgeable fire protection specialist be consulted. 


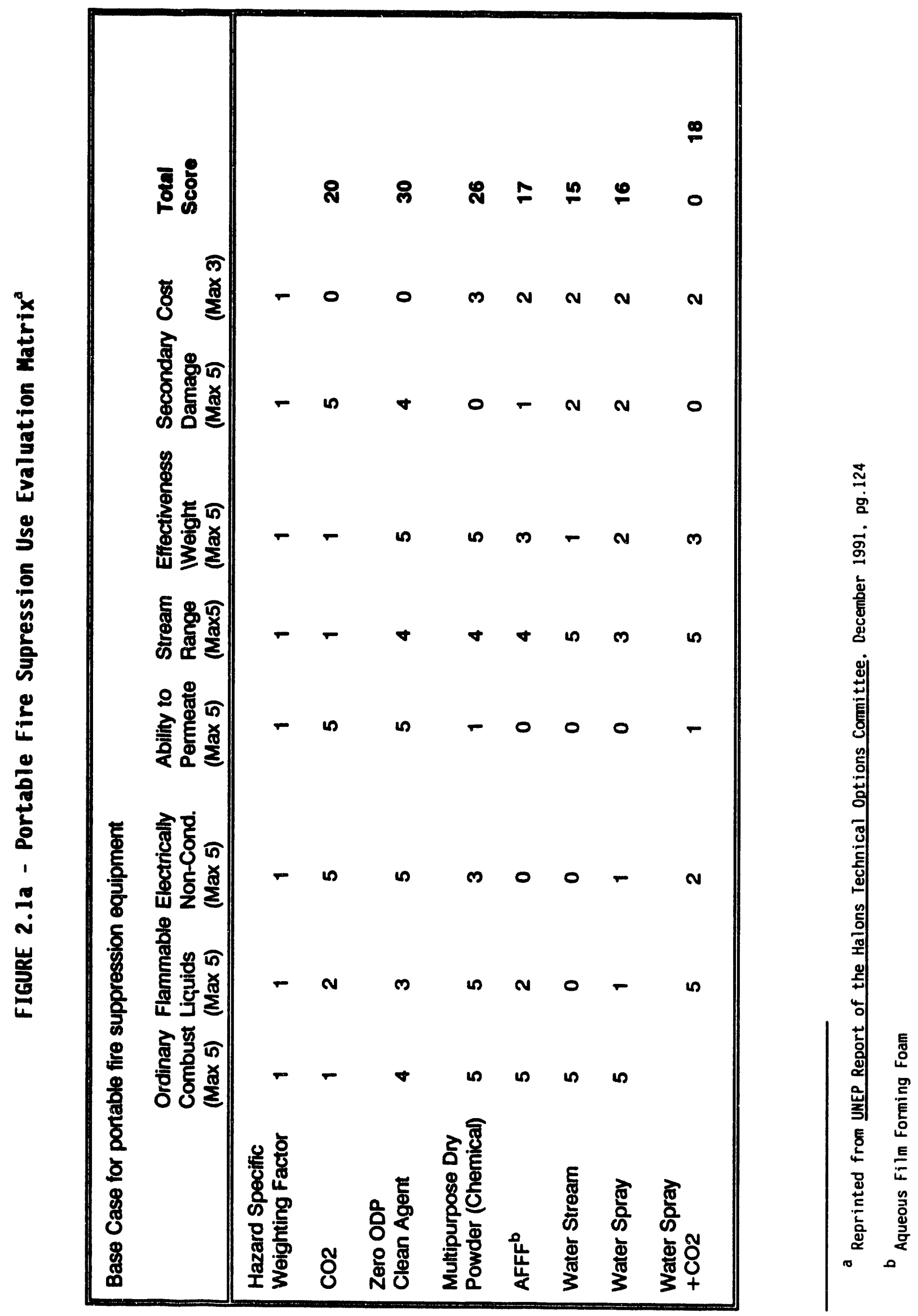




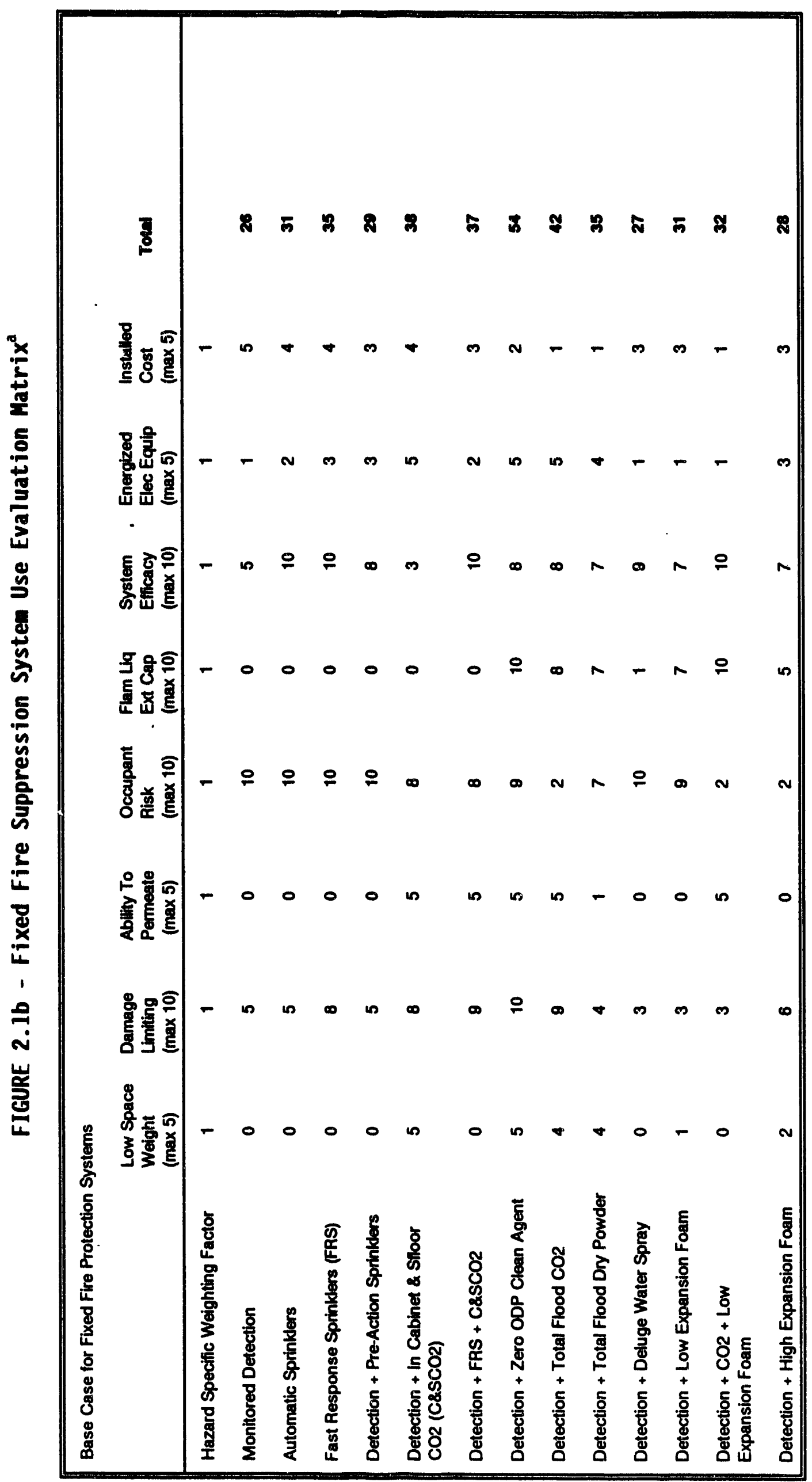


Monitored Early Warning Detection System

This system communicates with a fire department or constantly staffed facility. It provides rapid response to a fire and allows the fire to be extinguished at an early stage.

Because this system relies on mobilizing external forces for fire suppression, it would result in more damage to property than a system that included self-initiating suppression. It is also less effective and reliable than the halon total flooding system in its ability to prevent fire spread and explosion.

\section{Automatic Wet Pipe Sprinklers}

A network of water charged pipes (wet pipes) is installed throughout a protected structure, incorporating heat sensitive (fusible link) sprinkler heads spaced at regular intervals. An early warning detection system should be installed in combination with the sprinklers.

Sprinkler systems have a few technical disadvantages, but are the most reliable and least expensive automatic systems available. Automatic wet pipe sprinklers do not have as great an ability to permeate into areas that cannot be directly accessed as a gaseous fire suppression system. Greater direct and secondary fire damage is expected with sprinklers than with the total flood halon system. While automatic sprinklers are effective at putting out conventional fires, they are less efficient than some other systems at extinguishing liquid fuel fires. With certain materials, such as sodiun? metal, water could actually cause additional damage. There is also a critical concern regarding the use of water in areas containing fissile material.

\section{Fast Response Sprinklers}

These sprinklers limit the amount of direct fire damage by decreasing the lag time of the fusible link that activates the sprinkler head. Other mechanisms that can be used in conjunction with fast response sprinklers are early warning detection systems and isolation of the heating, ventilating, and air conditioning (HVAC) system to further minimize the delay of the sprinklers. Fast response sprinklers are comparable to automatic wet pipe 
sprinklers with similar advantages and disadvantages except that their use results in less fire damage to property and equipment.

\section{Pre-Action Sprinkler System}

This system is similar to conventional sprinklers except that it has a separate detection system. The piping is not charged with water. When a fire is detected, a valve opens, letting water into the system, which suppresses the fire.

Pre-action sprinklers are also similar to automatic sprinklers in their advantages and disadvantages, but are more costly and less reliable than the wet pipe systems.

\section{Deluge Water Spray}

A sprinkler sysiem with open heads is triggered by a separate detection system.

A water spray system is very effective at extinguishing normal fires but not so effective in extinguishing flammable liquid fires. A water-based system poses no threat of toxicity to humans. The limitations of these systems are similar to the other water-based systems.

\subsubsection{CHEMICAL SUBSTITUTES FOR HALON}

Many of the chemical substitutes for Halon-1301 and Halon-1211 are still undergoing extensive testing. For instance, the United States Air Force, in cooperation with the other military services and the Environmental Protection Agency, has already screened over 700 chemical compounds (Floden 1992). Some of the substitutes have not previously been used for fire suppression, and others are recognized agents currently used in fire suppression systems. Direct Halon-1301 Substitutes with a Small or Zero Ozone Depletion Potential $(0 D P)$

A number of chemical manufacturers are developing and producing potential replacements for Halon-1301 and Halon-1211. These replacements, however, are currently in the testing and development stages, with full commercial availability at least two to three years away. 
Great Lakes Chemical Corporation has developed two agents intended to replace Halon-1301 in some halon fixed-system installations (Settimo 1991). The Firemaster 100 (FM-100) agent is commercially available but is restricted to normally unoccupied areas, pending further toxicity testing. Using FM-100 would normally require replacing the gaskets and 0 -rings in the halon containers. In addition, FM-100's ODP is estimated to be 1.1 (as compared with 10 for Halon-1301), which is similar to the ODP of several Class I substances. For this reason, EPA may not approve its use as a safe alternative under Section 612 of the Clean Air Act, as amended.

Great Lakes' other agent, FM-200, should not have this problem. The manufacturer states that this patented chemical possesses an ODP of zero, extinguishes fire at the same concentration as Halon-1301, and is expected to be available in 1993. Its suitability for occupied areas requires further toxicity testing.

Atochem North America, Inc., is working on a new, zero OD? product, expected to be available in commercial quantities by 1995 (Settimo 1991). As with certain other zero ODP agents, it is likely to require double the concentration of this agent (compared to Halon-1301) to extinguish the same fire. The manufacturer calls interim toxicology results "encouraging."

The Dupont Company has announced a potential substitute ${ }^{(a)}$, FE-13, a chemical that possess an ODP of zero, and has low toxicity. It is already in use as a refrigerant. It does have a potential drawback: its high vapor pressure does not allow its use with standard halon piping.

\section{Carbon Dioxide $\left(\mathrm{CO}_{2}\right)$}

A total flood carbon dioxide $\left(\mathrm{CO}_{2}\right)$ system could provide a concentration of sufficient $\mathrm{CO}_{2}$ to extinguish a fire in all areas of an enclosure. The system would be triggered by an early warning detection system.

The characteristics of $\mathrm{CO}_{2}$ parallel $\mathrm{Hal}$ on-1301 in terms of its low electrical conductivity, ability to extinguish fires in areas that cannot be directly accessed (e.g., inside an electronics cabinet), and minimal secondary damage. $\mathrm{CO}_{2}$ is as effective as halon-based systems at extinguishing ordinary

(a) Daniel Moore, DuPont, personal communication, 1992. 
fires and as effective at extinguishing flammable liquid fires. Unfortunately, $\mathrm{CO}_{2}$ is an asphyxiant, and accidental releases in confined, inhabited spaces could be deadly. Care must also be taken to avoid damage that could result from the low temperatures usually present ir. the nozzle areas during discharge.

A variation of the total flood $\mathrm{CO}_{2}$ system is the in-cabinet and subfloor $\mathrm{CO}_{2}$ system. This is a hybrid system that combines a total flooding $\mathrm{CO}_{2}$ system for spaces under floors and an independently started $\mathrm{CO}_{2}$ system in individual equipment enclosures. A separate early response detection system is used for each. This system could also be combined with fast response sprinklers.

The advantage of the in-cabinet and sub-floor $\mathrm{CO}_{2}$ system is that it poses a much smaller risk to personnel. The disadvantages of this system are that it is not always effective and reliable and is not able to extinguish flammable liquid fires. When combined with fast response sprinklers, the system becomes more than three times as efficient as it is without the sprinklers.

For portable fire suppression, $\mathrm{CO}_{2}$ is the chemical that is least effective at extinguishing ordinary combustibles. It is less effective at extinguishing fires involving flammable liquids than Halon-1211 and multipurpose dry chemical extinguishers. $\mathrm{CO}_{2}$ systems are not so costly as Halon-1211 systems and have a shorter range. $\mathrm{CO}_{2}$ also has a lower effectiveness-to-weight ratio than Halon-1211 or multipurpose dry chemicals. Multipurpose Dry Chemicals

Multipurpose dry chemical extinguishers have the greatest ability to extinguish fires involving ordinary combustibles or flammable liquids. They are even more effective than Halon-1211 and are not electrically conductive. However, multipurpose chemicals are inefficient at permeating areas that cannot be directly accessed. The biggest concern with multipurpose dry chemicals is that their use can result in a high degre? of secondary damage, requiring extensive clean-up. 


\section{Low Expansion Foam}

A low expansion foam system is similar to the deluge water system, but uses agents such as Aqueous Film Forming Foam (AFFF) concentrate added to the water supply to increase its effectiveness. This system can prevent reignition of pooled flammable liquid by forming a residual vapor-suppressing film on the liquid surface.

Low expansion foam sprinkler systems are similar to deluge water spray systems, except that they are more effective at extinguishing flammable liquid fires. A combination of low expansion foam and $\mathrm{CO}_{2}$ gives the added benefit of being able to permeate hard-to-access areas and of being extremely effective at extinguishing flammable liquid and other types of fires. When used on energized electrical equipment, low expansion foam can produce shorts and shock hazards due to the water content.

In portable fire suppression, AFFF is very successful at extinguishing ordinary combustibles, but not so effective as Halon-1211 or multipurpose dry chemicals at extinguishing flammable liquids. While AFFF has a good range, it is electrically conductive and does not have the ability to permeate areas that cannot be reached directly. The use of AFFF can also result in a good deal of secondary damage due to the water in the system.

\section{High Expansion Foam}

This foam can expand in ratios of 500-1000 to 1 and has threedimensional fire fightirg capabilities. The system can be used for a wide range of fires involving flammable liquids and ordinary combustibles.

High expansion foam is less damaging to property than water or low expansion foam.

\section{Straight Stream Water}

Portable extinguishers using straight streams of water are very effective at extinguishing ordinary combustibles, but they are not effective at putting out flammable liquid fires. While straight stream extinguishers have an excellent range, they are electrically conductive, do not permeate areas that cannot be reached directly, and can cause secondary damage. 


\section{Water Spray}

Portable extinguishers using a water spray are excellent for extinguishing ordinary combustibles but are not very effective at putting out flammable liquid fires. Water sprays have a 1 imited range, are electrically conductive, and do not permeate areas that cannot be reached directly. Use of water spray extinguishers can also result in secondary dainage.

\section{Combination of Water Spray and $\mathrm{CO}_{2}$}

In portable extinguishers, this combination is excellent at extinguishing ordinary fires and is better at extinguishing flammable liquids than water spray alone. Because of the $\mathrm{CO}_{2}$, areas that are not able to be reached directly can be accessed more easily. This combination has a limited range and can result in secondary damage and subsequent clean-up requirements.

\subsubsection{CONSERVATION OF HALON}

Conservation is the term used for several control options that would reduce or eliminate the release of halons in existing fire protection systems operations over their lifetimes. These options include decreased training with halons, increased recovery of halons, decreased frequency of system teardown, reduced or contained discharge of halons during manufacturing of systems, and alternative testing gases and procedures. These controls offer a reduction in haton emissions at low cost, and they can be used for Halon-1301 total flooding systems and Halon-1211 portable extinguishers.

Currently, halons are recovered from total flooding systems at service and disposal, but recovery effectiveness can be increased using refrigerated recovery rigs. There is extensive research being conducted on halon recovery in the private sector. Results of this research and development (R\&D) are just beginning to become available.

\subsection{USE OF CFCS IN REFRIGERATION AND AIR CONDITIONING}

In most respects, DOE uses of CFCs in heating and cooling (air conditioning) technologies parallel the uses found in industry. DOE uses include air conditioning and refrigeration, applications associated with human comfort, process loads such as food storage, and mobile applications 
(including motor vehicle air conditioning). Some specialized applications are. associated with the use of exotic materials, radioactive substances, and large scale applications such as isotopic separation. The primary refrigerants used in all of these processes are CFC-11, $-12,-114,-500^{(a)},-502,-503$, and HCFC-22. Other refrigerants reported used by DOE in cooling applications include CFC-113, CFC-116, and HFC-134a, but these are limited to a few sites and do not constitute large usage or emissions.

\subsubsection{COMFORT COOLING}

A large portion of DOE refrigerant use is associated with cooling (space conditioning) for human comfort in buildings. The cooling equipment used is similar to that found in private industry and suffers from the same operational problems. These problems include leakage, seal failures, losses through air purge systems, losses during recovery and recycling of refrigerant, arid losses because of operation and maintenance requirements. Consequently, alternatijes to CFC uses in private sector building systems will be directly applicable to DOE buildings.

DOE's specialized building applications include those associated with advanced R\&D and with nuclear materials production, such as special climate control for laboratory applications (including clean rooms), positive pressure chambers, environmental chambers, cooling solvent tank condensing coils, and chemical process temperature control. These processes also mirror those used in similar facilities in private industry.

Mobile Air Conditioners (MACs) make up a portion of DOE's CFC use. Currently, the majority of these systems use CFC-12 as a refrigerant. The world's manufacturers have committed to changing the systems to eliminate the use of CFC- 12 as a refrigerant, and by the end of 1995 new vehicles are expected to use HFC-134a.

\subsubsection{REFRIGERANT APPLICATIONS}

Many different types of cooling systems and equipment are available for comfort applications in DOE buildings. Most of these employ a basic vapor compression system containing a compressor, a condenser, and an evaporator,

(a) The 500 series CFCs are azeotropic binary mixtures of halocarbon (CFC) compounds. 
and they use a refrigerant (usually a CFC) to transfer heat between the interior and exterior of the building. The system components come in many sizes and variations, depending on the intended system function, actual application, and building conditioning loads. The method used to compress the refrigerant may include centrifugal units, reciprocating systems, screw compressors, or sealed unitary systems, which contain all the system components in one unit. Each system employs one of several available refrigerants, depending upon the type of system components. These systems use some type of heat exchanger to effect heat transfer with the refrigerant, or ihe systams employ a secondary working fluid (e.g., water or brine) to transfer heat between the refrigerant load and the space being conditioned.

The general range of capacities of compressors and types of refrigerants used is shown in Figure 2.2. Specific equipment information should be obtained from the manufacturers.

\subsubsection{ALTERNATIVES FOR REDUCING CFC USE IN REFRIGERATION AND AIR CONDITIONING}

Plans for CFC phase-out in various refrigerant applications should include refrigerant recovery, recycling and other conservation practices to immediately eliminate unnecessary emissions of CFCS and subsequent purchases of replacement CFCs. Recovery, reclamation, and recycling will ensure a reserve of recycled CFCs that can be used to service existing capital equipment and for interim use until end-of-useful-life or renovation/ replacement of the equipment occurs. Recycling technologies for many largescale applications of CFC-12 and CFC-502 refrigerants have existed for many years and may be able to be used on current equipment. Recycling can occur either onsite or offsite. The first consideration in reducing CFC use is to stop leaks. All refrigerant-containing parts of all systems should be carefully checked for leaks and, when found, the leaks should be appropriately sealed.

Chillers also lose refrigerant during normal operation due to automatic systems' purging. New purge systems can reduce the refrigerant losses associated with this process by up to 98 percent. After system sealing, available CFCs must be conserved. 


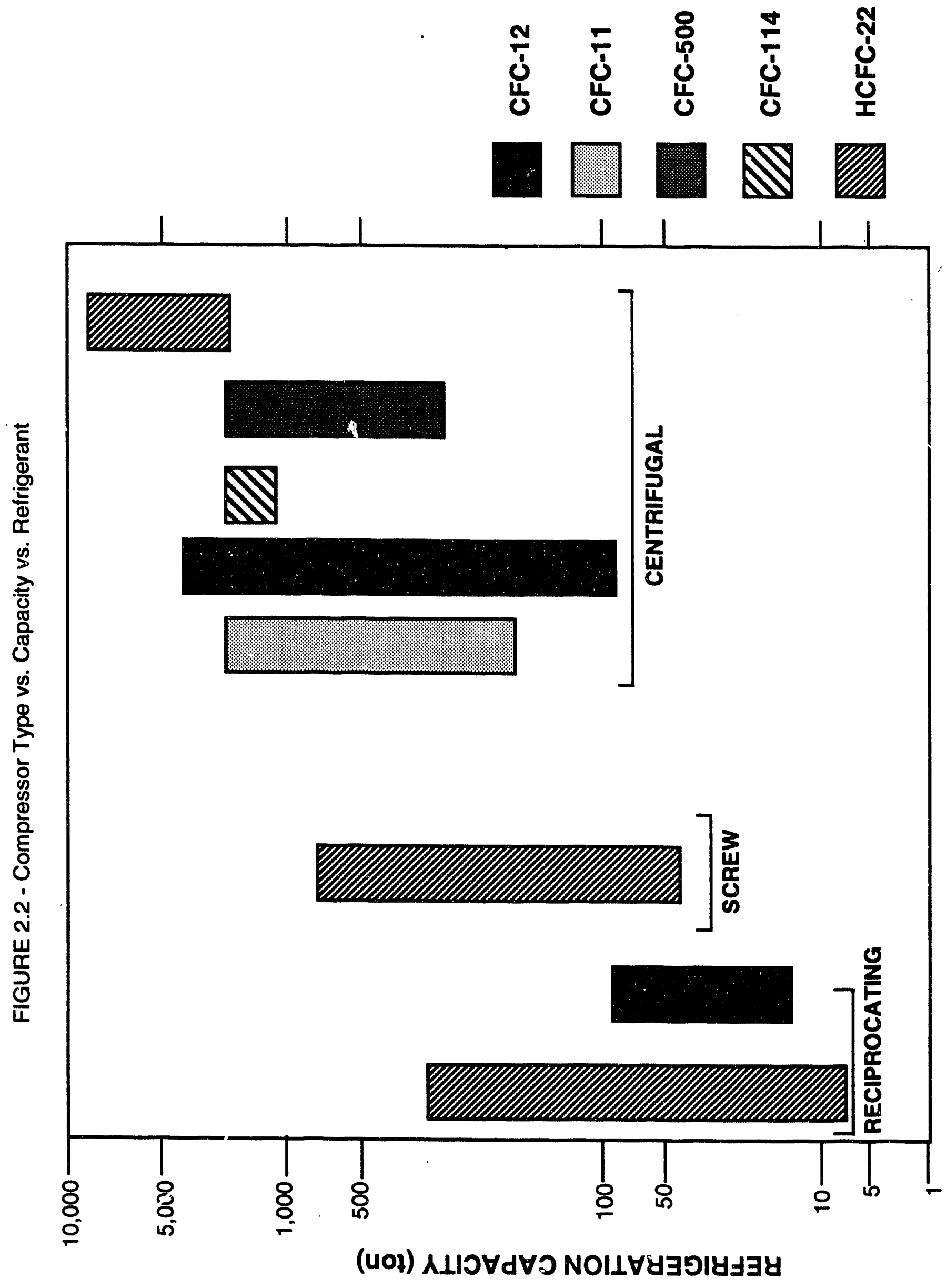

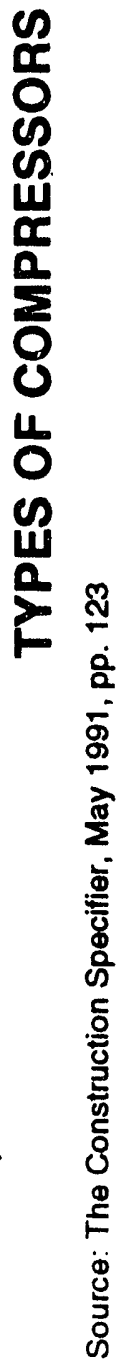


Many industrial facilities employ a stationary receiver tank that temporarily stores CFC-11 refrigerant while the system is being repaired. Receiver tanks help avoid venting of the refrigerant to the atmosphere and collect refrigerant for reclamation. They can reduce CFC emissions during servicing by 75 to 85 percent. Similarly, many C.FC-114 chillers were designed with receivers to store the entire refrigerant charge during major servicing or when the equipment is idle. Recovered refrigerant can also be transferred to holding tanks and shipped to offsite facilities for recycling and reclamation. Offsite recycling and reclamation is often one of the more efficient means of recycling refrigerant from large systems.

Portable recycling units generally process 1 to $4 \mathrm{lb} / \mathrm{min}$ and are used for systems with charges ranging from a few ounces to several hundred pounds. Portabie units are appropriate for uses such as office building chillers and refrigerated transport. Where portable units are too small, onsite recovery and recycling can be accomplished by use of a skid-mounted or a truck-mounted unit. These systems are moved as close to the source as practical and connected to the refrigeration system with hoses.

Equipment is available to recover and recycle CFC-12 refrigerants from vehicles with MACs. Prior to the 1990 Clean Air Act Amendments (Sections 608(c) and 609), these refrigerants would normally have been vented to the atmosphere during servicing and/or repair. The Clean Air Act, as amended, makes it unlawful to knowingly vent, release, or dispose of any $\mathrm{Cl}$ ass I or Class II substance or substitute in the course of servicing, repairing, or maintaining equipment. Recently, a standard of purity for recycled refrigerant has been accepted by automobile manufacturers and published by the Society of Automotive Engineers (SAE) as SAE J-1991 (1991). SAE has developed two other industry standards for the recovery and recycling of CFC-12 from MACs: SAE J-1989, "Recycling Servicing Procedures for the Containment of R12" (1989), which provides guidelines for service technicians, and SAE J-1990, "Extraction and Recycle Equipment for Mobile Air Conditioning Systems" (1990), which provides equipment specifications for CFC-12 recycling and/or recovery and for recharging systems.

Underwriters Laboratcries (UL) certifies recovery and recycling machines that meet the SAE standards in addition to several safety criteria. As of 
August 1992, 116 models from 40 different recycling equipment manufacturers have been approved by UL. The Air Conditioning and Refrigeration Institute (ARI) has also developed a purity specification for CFC-12. This specification, ARI 700-88 (1991), "Specification for Fluorocarbon Refrigerants," has even stricter requirements for recycled refrigerants. SAE $J-1991$ requires that recycled CFC-12 supplied in containers from other recycle sources (i.e., non-MACs) must meet the more stringent ARI 700-88 standard. Recycling is expected to reduce MAC CFC emissions at servicing by 90 percent or more. Servicing the remaining systems with CFC-12 will be strictly regulated to recover and recycle the old refrigerant and prevent emissions. (See Figure 2.3 for a list of EPA-approved servicing equipment.)

Available Alternative Refrigerants

With the recognition that CFC production will cease and the availability of existing supplies will diminish, the importance of substitutes for CFCs becomes evident. Substitute or alternative refrigerants include virtually any fluid or gas; however, some are preferable to others for economic, safety, and technical reasons. Even air, ammonia, and propane can be used as refrigerants. Ammonia systems, for instance, are already utilized in some industrial applications, such as cold storage, that are rarely in contact with occupied spaces. Ammonia biodegrades quickly and has zero ozone depletion potential. It is, however, toxic to humans above certain concentrations and flammable in concentrations of 16 to 25 percent by volume in air (UNEP 1989d). Harmful concentrations are easy to detect because of ammonia's pungent odor, thereby facilitating the repair of leaks and the evacuation of personnel. Because of the toxicity concerns associated with ammonia systems, equipment rooms must be isolated and monitored for leaks. When new equipment is being considered, it may be appropriate to consider such a system, commensurate with use.

Lithium bromide (absorption) systems are possible replacements for CFCbased chillers. Such systems can be gas-fired or powered using waste heat at the correct temperature. These systems are also currently available. Other al ternatives include HCFC-22, HCFC-123, HFC-134a, and numerous others currently being developed, tested, and evaluated. HFC-134a, which has an ODP of zero and has undergone extensive thermodynamic research as a promising 
FIGURE 2.3

EPA-Approved Recycle Systems

for Mobile Air Conditioning ${ }^{a}$

Manufacturer

Sun Electric Corp.

White Industries - DV. of K-Whit Tools. Inc.

SPX Corporation

Robinair DW.

IG-LD. Inc. Sub. of Valvoline Inc.

Refrigerant Technologies Inc.

Refrigerant Recovery Systems, Inc.

Technical Chemical Co.

Belco Controls Inc.

Wynn's Climate Systems, Inc.

James Kamm Technologies Inc.

Assembly Systems Corp.

Environmental Technologies Corp.

AES NTRON

Power Manufacturing

MDI

Four Seasons

Environmental Products Amalgamated Pty. Lid.

Airosol Company Inc.

Myers Enterprises

Carrier

Van Steenburgh Engineering Lab Inc.

Promax Industries Inc.

Mastercool U.S.A. Inc.

Rolo Inc.

International Carbonic Inc.

Classic Tool

P\&F Technologies Ltd.

Ozone Saver Industries Inc.
Model

MRC-150, $-300,-400,-500$, MTC- 4000, NAPA$1100,-5000$, A9S50, ATC-1000, $-1100,-5000$,

01050, 01060, 01061, 01080, 01095

17251C, 014-00900, 17500B, 17501B, 17503B

$173-00,-01,-03,-50,-50 \mathrm{C},-51,-51 \mathrm{C}$,

$174-00,-01,-03,-25,177-00,-01,-03,-15,-25$

1400,1500 ,

RRC-1000, RRC-750, RRC-750X

ST100A

SERCON $8000,9000,-9000 A,-9220$,

08

90-0001A, -0458A

K-3333, K-3333-TB.

NS-2000.

SYSTEM I 102-12

Retrlever 2.2A

R-12a

1/2 HPCA

59900

SKYE.EP3, SKYE EP-4/5

Chargette RC2000

MR-1991-A, MR-1991-R

12RA001100

JV90-4, -3, -2, -1, LV30-4, -3, -2, -1, CV15-4, -3, $-2,-1$

ROGER-1 (consisting of "Front" and "Back"

Sections)

Supervamp 62000

9IRI2

RRR-SS, BH-RRR

FBR-II

PF-8

R-6A, OS-2000

MULTIPLE LISTINGS

Company

Atlas Supply Co.

Ford Motor Company

Four Seasons

Snap-On Tools Co.

NAPA Temp. Products

MAC Tools, Inc.

Carquest Corp.

NAPA

Dowmar Solvent Recovery Systems Inc.

Ig-Lo, Inc. Sub. of Valoline

Environmental Systems Products, Inc.

\begin{tabular}{l} 
Model \\
\hline 209990 \\
EAC-205, -250,-750,-1400,-1500 \\
$158-00001,-00002,01400900$ \\
59870 \\
ACT2500, ACT 3000, ACTH 3000 \\
ATC1100,-5000 \\
ACRRC-750, AC650 \\
209990 \\
209990 \\
DR12R \\
1000 \\
FICS9000
\end{tabular}

A UL Multiple Listing (referred to as private labeling by the industry) is the formal publication of the name of a company that appears on equipment that is basically UL Listed for another company. It would be similar to a private brand except that the basic company name need not appear anywhere on the products.

'Undenwriters Laboratories, Inc., January 23, 1992 and August 13, 1992 
al ternative refrigerant for MACS, has also been tested by the U.S. Navy for larger refrigeration applications. It is currently being used in some 1992 model automobiles for Jeep and Mercedes Benz (Mei 1991).

HCFC-22. HCFC-22-based refrigeration systems can be used as a replacement for CFC-502 systems. HCFC-22 has been thoroughly tested as a refrigerant, and a two-stage unit is currently available for use in commercial systems. Because HCFCs will eventually be phased out, they should be considered as only transitional solutions. DOE Order 6430.1A, General Design Criteria (April 6, 1989), provides guidance to reduce DOE CFC use in HVAC systems. Under this order, continued installation of HVAC systems using CFC$11,-12,-113,-114,-115,-500,-501$, or -502 is considered operationally and environmentally unacceptable. DOE's policy is to limit new equipment to, and where feasible replace existing equipment with, equipment designed to use HCFC-22. This policy will be updated as new, proven, technologies become commercially available.

HCFC-123. HCFC-123 is currently being tested as a substitute refrigerant for CFC-11 in commercial chillers. HCFC-123 is a virtual "dropin" substitute for CFC-11 in most open shaft applications, with only minor system material changes required to retrofit existing CFC-11 units. A manufacturing plant for HCFC-123 has recently been built in the United States. Capital costs of new packaged units are competitive with CFC-11 systems; however, because HCFC-123 is 5-20 percent less efficient than CFC-11, the operating costs may be higher.

HFC-134a. This is the accepted replacement for CFC-12 in MACs. In 1991 some European, Japanese, and American automobile manufacturers reportedly began using this new refrigerant in their MACs. HFC-134a is not, however, a drop-in replacement, and system changes are necessary for a successful conversion to this refrigerant. While new plants are under construction, $4 F C$ $134 a$ is currently commercially available in limited quantities. In addition, HFC-134a use is expected to be more expensive than CFC use due to higher capital and energy costs. SAE has developed a purity standard, J-2099, for use in HFC-134a recycling from MACs. An important consideration in evaluating HFC-134a as a substitute is that it could significantly contribute to greenhouse-effect global warming, both directly, due to its relatively long 
lifetime (20 years) and its significant global warming potential (GWP), and indirectly, as a result of its lower energy efficiency. The long term outcome of this situation is unclear.

New Equipment

The development of alternative refrigerants to CFCs does not signal the end of equipment technology development. Recognizing that all of today's existing equipment will ultimately need replacement, the availability of environmentally safe refrigerants and new technologies will be the key to achieving a long-term solution to the problem. New equipment installed today can be expected to need replacement by 2025 .

Currently chillers that can use either a CFC or certain non-CFC refrigerants are being manufactured. One manufacturer currently ships 80 percent of its units with dual refrigerant capability. This facilitates the use of a CFC in the short term and allows for a simple conversion at some future time. As further refrigerant research is conducted, additional options should become available.

New equipment is also becoming more efficient. Consideration of required cocling loads when replacing existing equipment may lead to use of smaller capacity cooling equipment, resulting in a decrease in the amount of refrigerant needed to serve the building. Non-CFC systems such as ammonia, lithium bromide, and others are also experiencing renewed interest and consideration. Advanced burner design for natural gas systems coupled with multiple staging can significantly increase the overall efficiency of many non-CFC systems, making them more economically attractive.

\section{Emerging Technologies and Substitutes ${ }^{(b)}$}

Extensive research and testing have been completed to identify potential substitutes for CFCs in cooling applications. Several new and reconsidered refrigerants exhibit the appropriate thermodynamic properties and meet toxicity, flammability, and energy-efficiency criteria. Many of the potential substitutes are currently undergoing testing and will be available for use when they are approved.

(b) See Appendix A - Possible Alternatives Being Considered for Review Under the SNAP Program. 
Iernary blends. One promising option to replace CFC-12 in large-scale refrigeration end uses is a ternary blend of HCFC-22 (36 percent), HFC-152a (24 percent) and HCFC-124 (40 percent). The ternary blend has thermodynamic properties which match CFC-12 very closely. Other advantages include a 3 percent or greater increase in energy efficiency compared to CFC-12. (UNEP 1991b). Certain CFC-12 and ammonia systems may also be retrofitted to use the ternary blend, (a) which is expected to become available by 1993. Replacement CFC-500 chillers will be constructed using a ternary blend of HCFC-22, HCFC-124, and HFC-152a that is currently being tested and should be available as early as 1993.

This same ternary blend of HCFC-22, HFC-152a, and HCFC-124 may also be an option for small scale refrigeration. It is essentially a zero cost option because of the significant energy savings derived from its higher energy efficiency (as much as three percent). The U.S. Navy has conducted testing on buth HFC-134a and an HCFC-22/HCFC-124/HFC-152a blend in a small CFC-12 chiller.

HCFC-22. As previously discussed, HCFC-22, with an ODP of 0.05 , is an interim replacement for CFC-502 and CFC-12 in new commercial refrigeration systems. Alone or in a blend, it can be used in both medium and low temperature systems, such as cold storage-type applications. In CFC-502 replacements, system redesign or compressor modification will be required to permit HCFC-22 use. HCFC-22 in liquid injection compressors is currently available to replace CFC-502.

HFC-152a. For small-scale refrigeration (10-50 tons), near- and midterm alternatives include ternary blends, HFC-152a, and nonazeotropic refrigerant mixtures. Combinations of commercially available and acceptable fluids in nonazeotropic refrigerant mixtures may be used as CFC substitutes. HFC-152a is available as an alternative refrigerant and has been proven as a possible replacement for CFCs. HFC-152a is moderately flammable but has excellent thermodynamic characteristics.

(a) The ternary blend is a viable option for use in retail food systems with high leak rates only if a secondary fluid is used for heat transfer in enclosed occupied spaces. This is because there is often preferential boiling in such systems, and hence recharging with a blend of the same composition will change the capacity and performance of the system. 
An azeotropic blend of HFC-32 and HFC-125 was recently announced as a promising substitute for $\mathrm{CFC}-502$ in low and medium temperature refrigeration applications. Both HFC-32 and HFC-125 contain no chlorine and thus have zero ODPs. HFC-32 is flammable, but the blend is not. MAC systems may also be retrofitted to operate with near-azeotropic ternary blend refrigerants.

Cooling Cycles. Alternative cooling cycles may replace the traditional refrigerant-vapor compression cycle in some uses. For example, a modified Stirling cycle using a non-CFC refrigerant has been demonstrated in a working home refrigerator. The Navy is pursuing non-CFC refrigeration cycles for medium temperature refrigeration applications. Such technologies must be applicable to large scale cooling in order to be adopted by the industry.

HFC-134a. HFC-134a is a substitute for CFC-12 in chiller applications. HFC-134a may be employed in CFC-12 systems that are retrofitted to handle its characteristics, as well as in new systems.

HCFC-124. Chillers using HCFC-124 may replace CFC-114 in industrial and process chiller systems, al though this chemical has an ODP of 0.019 .

\subsection{USE OF ODSS AS SOLVENTS}

CFC-113, methyl chloroform (1,1,1-trichloroethane), and carbon tetrachloride are the major ODSs used by DOE as solvents in cleaning operations. The principal uses of these solvents are cleaning electronic components, precision cleaning (including nuclear decontamination), and metal cleaning. Of the three compounds, carbon tetrachloride is the least used, and discussions with facility personnel indicate that it is already being replaced in many DOE solvent processes. Chemical stability, low toxicity, and zero flammability have made CFC-113 the precision cleaning chemical of choice. Similarly, high solvency, moderate evaporation rate, and higher boiling point have made methyl chloroform a unique product for cleaning specific soils, such as heavy grease.

The choice of potential substitutes for these chemicals will depend on the site-specific uses to which the ODSs are currently put. Some of these alternatives may be able to be used with existing cleaning equipment, while others will require more extensive retrofitting or purchasing new 
technologies. The phase-out of methyl chloroform may herald a return to other chlorinated solvents and non-halogenated organic solvents. These substances tend to be more toxic, and their emissions are regulated as hazardous air pollutants under the Clean Air Act, as amended. Using them will require the use of low emission equipment and safety measures to protect workers. However, the phase-out of ODSs also provides an opportunity for improved cleaning performance and innovation in cleaning technology.

Because CFC-113, methyl chloroform, and carbon tetrachloride have been readily available and relatively inexpensive, they are often used in systems lacking recycle and recovery mechanisms to limit the release of the chemicals to the atmosphere. As production of these chemicals is phased out as part of the requirements of the Clean Air Act, as amended, the cost to obtain them is expected to increase dramatically. A major first step in reducing the consumption of ODS solvents is implementing recycle/recovery measures. The UNEP report on Solvents, Coatings, and Adhesives (1991) provides guidelines on solvent recovery that can reduce total solvent emissions by 90 percent. Using less solvent can be accomplished by periodic preventive maintenance, engineering controls, operator equipment training, and spill prevention techniques.

\subsubsection{ELECTRONICS}

The principal use of CFC-113 and methyl chloroform in electronics cleaning is to remove soldering flux residues after assembly. CFC-113 is used more often than methyl chloroform because the latter tends to degrade components. Until recently, military specifications (Mil-specs) and military standards (Mil-standards) created a major barrier to phasing out these substances. DOE and industry solvent uses tended to comply with Department of Defense (DOD) requirements even when they were not required to do so. In 1991, DOD modified Mil-standard 2000 to allow solvent alternatives to be used and recommended that CFC-based solvents be phased out. This change in DOD solvent requirements should make it easier for DOE and industry to pursue alternatives to ODS solvents. 


\subsubsection{PRECISION CLEANING}

Precision cleanine must be performed on equipment that requires an extreme level of cleanliness to keep the components operating effectively or that includes components sensitive to cleaning operations or having physical characteristics that make them difficult to clean. CFC-113's low surface tension and high volatility provide good wetting and penetration for particle removal. CFC-113 is also used as a carrier for thin film applications, where the lubricant is placed in a CFC-113 solvent solution and applied to precision pieces such as bearings. After the CFC-113 evaporates, a stable oil film is left on the precision part. Methyl chloroform is used in precision cleaning activities for the removal of specific soils.

Several options are available for reducing consumption of CFC-113, methyl chloroform, and carbon tetrachloride in precision cleaning; not all of the options will be viable for all precision cleaning operations.

Consideration must be given to the types of contaminants to be removed and the complexity of the components being cleaned. Alternative solvents may need to have a low surface tension, low viscosity, and relatively high vapor pressure in order to clean, and be removed from, blind holes, gaps, and areas with small clearances. As a first step in switching to an alternative cleaning process, consideration should be given to changing the existing equipment to enhance chemical recycle and recovery. Alternatives to CFC-113 and methyl chloroform include both solvent and non-solvent options. Solvent options are aqueous and semi-aqueous cleaning, HCFCs, alcohols, and synthetic aliphatic hydrocarbons. The non-solvent options are pressurized gas cleaning, supercritical fluid cleaning, plasma cleaning, and ultraviolet (UV)/ozone cleaning.

\subsubsection{METAL CLEANING}

Metal cleaning is an essential process in production, maintenance, and repair of manufactured components. CFC-113 and methyl chloroform are the solvents of choice for metal cleaning activities. They can be used on a wide variety of organic contaminants and are noncorrosive to the metals being cleaned. They are nonflammable, have a low toxicity, and are chemically stable. Their low heats of vaporization make them useful in vapor degreasing. 
Prior to the use of CFC-113 and methyl chloroform, chlorinated solvents such as trichloroethylene, perchloroethylene, and methylene chloride were used in many metal cleaning processes. Since trichloroethylene and perchloroethylene are regulated volatile organic compounds (VOCs) and hazardous air pollutants under the Clean Air Act, as amended, they will be viable only for applications in which their emissions can be tightly controlled. Because of concerns about metal corrosion and the need to remove extremely difficult soils, there is a perception that chlorinated solvents are the only viable alternatives for some uses. In these applications, best management practices can result in equivalent or better cleaning than CFC-113, while staying within regulatory limits (UNEP 1991c).

\subsubsection{ALTERNATIVES FOR REDUCING ODSS IN SOLVENT USE}

Alternatives for reducing or replacing CFC-113 and methyl chloroform include conservation and recovery, as well as the use of alternative solvents, solvent blends, aqueous cleaners, emulsion cleaners, mechanical cleaning, thermal vacuum de-oiling, and no-clean alternatives. Figure 2.4 identifies the alternatives for each solvent process.

\section{Recycle/Reuse}

While new processes and alternatives are being developed for ozonedepleting solvents, the use of reduction and solvent recycling options will al so become very important. The required production phase-out of CFC-113, methyl chloroform, and carbon tetrachloride will make these products increasingly more expensive and difficult to obtain. The same will be true for HCFCs that are used as interim substitutes. Commercial recycling facilities can recycle solvents from degreaser bottoms and still bottons having high contamination levels after onsite recycling. The recycled solvents can be returned to the site, thereby reducing purchase requirements.

For metal cleaning, gravity separators, water absorption, and single plate distillation are three techniques for recovering solvents. Use of best available technology can reduce solvent losses by up to 90 percent in some processes. The UNEP Report on Solvents, Coatings, and Adhesives (1991) provides guidance on the types of management practices to use for cold cleaning, vapor cleaning, and continuous in-line cleaning. 
FIGURE 2.4

Alternatives for ODS Solvents

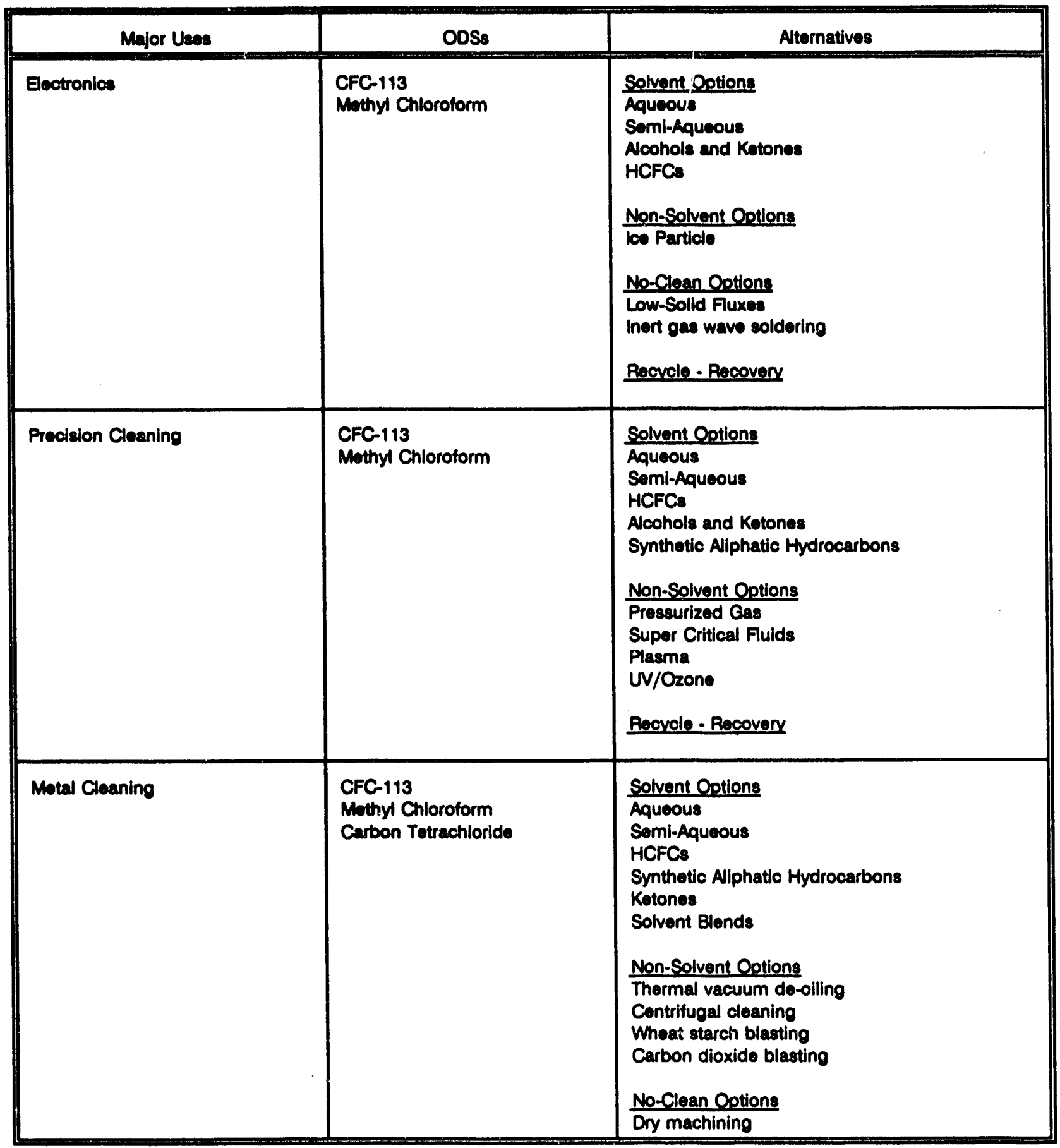




\section{Solvent Options}

Aqueous cleaners. These cleaners use water as the primary solvent and combine synthetic detergents and surfactants with special additives (e.g., builders, pH buffers, saponifiers). They cause fewer problems with worker safety than many other solvents, and they are not flammable or explosive. Aqueous cleaners also provide multiple degrees of formulation and concentration, allowing them to clean a large variety of components. Nuclear decontamination may be effectively achieved by an aqueous system and highpressure sand blasting. Using water-based cleaners is much more complex than using CFC-113 or methyl chloroform, and drying can present problems. The higher surface tension of water compared to CFC-113 and methyl chloroform increases the potential for solvents to become trapped in capillary spaces and blind holes. Some processes may require a separate drying section, and this may have a corresponding increase in energy consumption (EPA 1991b). This process can also result in large amounts of waste water that will need to be treated prior to disposal.

Aqueous cleaning systems can be designed using closed-loop recirculating wash and rinse stages as opposed to continuous discharge systems. This reduces the amount of waste water being produced and results in savings in energy and disposal costs. If water-soluble fluxes are used, "zero discharge" systems can significantly reduce water, energy, and disposal costs.

Aqueous cleaners are used with three general types of equipment: immersion, spray, and ultrasonics. Immersion equipment uses mechanical agitation to remove soils. This process can often run on existing vapor degreasing equipment with minor engineering changes (UNEP 1991c). The equipment is usually simple to operate and capable of cleaning complex parts. Spray equipment uses a high pressure spray for component cleaning or as a final rinse after immersion cleaning. Spray techniques are inexpensive and possibly more effective than immersion techniques, because contaminants can be filtered from the solvent prior to its being sprayed on the components. Ultrasonic equipment is the most expensive of the three aqueous cleaning options. It uses an ultrasonic wavelength to agitate soils from the components. The efficiency of the cleaning depends upon the ultrasonic power 
and the orientation of the components in the tank. Alternatives may be combinations of these processes.

Alkaline cleaners (aqueous cleaners containing alkaline salts) are viable, broad substitutes for CFC-113 and methyl chloroform. Approximately 60 percent of halogenated solvent degreasing operations for metals could be replaced with alkaline cleaners (UNEP 1991c). Many alkaline cleaners are currently available, and others are under development. They are effective in cleaning a broad range of soils on a wide variety of substrates. Other common active ingredients in aqueous cleaners include alkyl benzene sulfonates and other anionic surfactants. Corrosion inhibitors are added to minimize the effect of the solvents on metal surfaces. The general design of the equipment used in alkaline cleaning of metals is similar to that used in aqueous precision cleaning.

Semi-Aqueous Cleaners. In this category, hydrocarbon surfactants, such as terpene blends, are either emulsified in a water solution or applied in concentrated form and then rinsed. Both processes use water and are therefore semi-aqueous. An existing single- or multi-stage vapor degreaser may be able to be adapted for use with semi-aqueous cleaning processes. The semi-aqueous process uses flammable fluids that may require retrofitting of the heating elements on existing degreasers with automatic shut-offs and other safety features. Semi-aqueous cleaners are compatible with most metals and plastics and provide good cleaning for heavy soils, greases, and waxes (EPA 1990a). Semi-aqueous cleaners are similar to aqueous cleaners, with the exception that concentrated semi-aqueous cleaners should not be used in vapor or spray cleaning without an inert atmosphere or protective equipment because of their ignitability. Underwater spray immersion, spin-under immersion, and ultrasonics are recommended application methods.

These hydrocarbon surfactant cleaners (including terpenes and glycol ethers) can be used in metal cleaning applications where high viscosity, high molecular weight soils, or semi-solid soils are associated with corrosion sensitive substrates. They are potentially less expensive to purchase than CFC-113 and methyl chloroform (EPA 1991c). 
As with aqueous cleaning, semi-aqueous cleaning methods can result in significant volumes of waste water that may need to be treated and discharged. Some hydrocarbon surfactant cleaners can be easily separated from the rinse water, allowing the rinse water to be recycled or reused. The hydrocarbon surfactant wastes may be able to be burned as fuel (UNEP 1991c).

Hydrochlorofluorocarbons (HCFCS). Several HCFCs have been proposed as potential substitutes for CFC-113 and methyl chloroform. These include HCFC$225 \mathrm{ca},-225 \mathrm{cb},-141 \mathrm{~b},-123$, and blends. These compounds have a lower, but still significant, ozone-depleting potential than CFCs, primarily due to the shorter atmospheric lifetime of each compound's molecules. Because many of these HCFCs are also targeted for phase-out, they should be considered transitional alternatives, and the costs of eventual phase-out should be evaluated.

HCFCs have the advantage of possessing many of the same physical properties as CFCs, including low surface tension and nonflammability. The HCFC compounds may, therefore, be able to be directly substituted into current processes. HCFCs are also relatively expensive, and their availability will greatly limit their viability as alternatives for CFC-113 and methyl chloroform. According to the 1991 UNEP report on Solvents, Coatings and Adhesives report, both DuPont and Allied Signal have indicated that they will no longer manufacture HCFC-123. In addition, DuPont does not plan to offer any products containing HCFC-141b.

The HCFC-225s are compatible with most metals and plastics, but are incompatible with acrylic resins. Recovery systems for CFC-113 can be applied to the HCFC-225s, and there are also HCFC-225 recovery systems that exhibit a 95 percent recovery rate (EPA 1990b). Because they are volatile compounds, a recovery system will be required. The HCFC-225s are considered equivalent to CFC-113 in their cleaning ability.

Alcohols and Ketones. As polar chemicals, alcohols are very strong solvents. The primary concern with alcohol use is its combustibility; equipment must be both $f l$ ameproof and explosionproof to prevent injury to workers and equipment. Acetone and isopropanol have been identified as possible substitutes for CFC-113. Methyl, ethyl, and isopropyl alcohols have 
been used in precision cleaning for removing resin and polar activators common in flux. A perfluorocarbon (PFC) "blanket" is used to render the alcohol vapor inflamable. Both alcohol and PFC leave no residues, so solvent operations generaily do not require drying. Relatively small amounts of alcohol are required for cleaning. The disadvantages to this option are the high global warming potential of PFC and the high capital cost of the equipment. Additional costs may result from the need to design systems capable of automatically shutting off if the PFC level drops below the level required to prevent explosion. Ketones, such as acetone and methyl ethyl ketone, are also powerful solvents. However, their incompatibility with many structural polymers and their extreme flamability render them unlikely al ternatives for large-scale uses of CFC-113 or methyl chloroform.

Aliphatic Hydrocarbons. A wide range of al iphatic hydrocarbons (petroleum distillates) are used in precision clearing. This process does not use water and therefore is safe for water-sensitive components. Aliphatic hydrocarbons are effective at cleaning a wide variety of soils, and the low surface tension allows good penetration of component parts. Generally, hydrocarbon cleaning can be performed in modified aqueous cleaning equipment. Because they contain Vocs, solvent vapors will need to be recovered using either carbon adsorption or condensation techniques. The solvents can be cleaned for reuse by filtration or distillation with a high rate of recovery. Non-Solvent Options

Pressurized Gas. Gases that may be used for precision cleaning include air, rare gases, carbon dioxide, chlorodifluoromethane (HCFC-22), and nitrogen. Depending on the gas selected, they are characterized by lox toxicity, high diffusivity, and low flammability. Of the gas options, air is the most reactive because of its high oxygen content. Rare earth gases are characterized by their extreme chemical inactivity and may be obtained by fractionation of liquid air or direct purchase. Carbon dioxide is relatively stable but may dissociate into carbon and oxygen at high temperatures. It is a byproduct of numerous processes, but care must be taken in its use since it is an asphyxiant and can be toxic to humans. HCFC-22 is a ronflammable gas that is generally used in its liquified state. Continual flooding of a component with liquid HCFC-22 can freeze off some contaminants. Although it 
is believed to be nontoxic, high concentrations can result in dizziness, narcosis, and nausea. Nitrogen may react with certain metals.

A difficulty in using high pressure gases is the need to maintain pressure. In addition, some components may be harmed by soil particles that are removed and carried along with the gas. A vacuum may be used to capture the dislodged contamination. High efficiency filters may also be necessary to collect contamination.

Supercritical fluids (SCFs). This is a special category of pressurized gases that inciude fluids above their critical values for temperature and pressure. SCFs are flexible solvents because small alterations in pressure and temperature can produce significant changes in density, creating a corresponding change in the solvent power. SCFs are characterized by high diffusivity and low density and viscosity. Supercritical carbon dioxide has been tested by several users as a potential replacement for CFC-133 and methyl chloroform. Supercritical carbon dioxide can dissolve many hydrocarbons, esters, silicones, perfluorinated soils, halocarbon-substituted triazines, and polychlor- and bromo-trifluoroethylene. Particulates such as lint, dust, metal, and salts are insoluble in supercritical carbon dioxide but may be dislodged. SCFs are particularly effective at removing soils with medium molecular weight and relatively low polarity.

Plasma Cleaning. A plasma is an electrically charged gas containing ionized atoms, electrons, highly reactive free radicals, and electrically neutral species. Plasmas are created by passing an electric current through a process gas, and they are characterized by high reactivity. Because process gases are inexpensive and nontoxic, this application has a relatively low operating cost. However, initial capital costs are high, and the equipment is highly specialized. cleaning time can vary from minutes to hours, but all parts are cleaned evenly and equally well regardless of their size or shape. A plasma cleaning system consists of a reactor, radio frequency generator, and a control system. The specific gas to be used in a plasma cleaning system will depend on the components to be cleaned. Plasma has been used for removing organic contamination and residue from substrates, residues from plating baths and washing solutions, and conformal coating to repair circuits. 
UV/Ozone Cleaning. In this process, components are exposed to UV light in the presence of ozone. The process can be used with a variety of surfaces, including glass, quartz, mica, ceramics, metals, silicon, and polyamide cement. Components must be tested to determine the optimal orientation to the UV light source. This process requires no moving parts and is therefore easy to maintain and operate. Extensive exposure to UV light or ozone can be hazardous to humans, and this may require special design considerations. Further development and testing of this process is necessary to identify the cleaning processes for which it would be most applicable.

Thermal Vacuum De-oiling. This system uses a heated vacuum to remove oil by vaporizing the oil. The vapors are then pumped into a cold trap where they condense and can be collected for recycle or disposal. This technology can be used to clean parts following cutting, machining, quenching, and stamping. Vacuum de-oiling is advantageous because it uses no solvents, allows for removed oils to be recycled, and is simple to operate. Because the ability to volatilize oil is temperature- and pressure-dependent, the equipment is set to the temperature and pressure required by the oil being removed. This may require numerous changes to the equipment settings in facilities that are not cleaning metal parts of a consistent size and contaminant level.

No-clean Alternatives. For electronics, several "no-clean" alternatives to the use of solvents require changes in the materials used for soldering to reduce flux residues that need to be removed from the component. Low solid fluxes contain only 1 to 5 percent rosin or resin as opposed to the 15 to 35 percent for high solid fluxes. They are commercially available for foam, wave, or spray applications and are being considered by the DOD for certain uses. Inert gas wave soldering operates under either a nitrogen atmosphere or in a vacuum. The system operates without conventional rosin or fluxes, and has the advantage of reducing the amount of oxidation on components both before and after soldering. Post-cleaning is eliminated for many uses. Preliminary tests of inert gas, or controlled atmosphere, soldering have demonstrated no significant differences in the quality of solder joints. Electronic cleaning may also be able to take advantage of a new technology 
developed in Japan that uses ice particles ranging from 0.1 to 300 microns in diameter to remove contaminants.

For lower grade metal cleaning requirements, various mechanical methods, such as brushing and wiping, are viatle alternatives to solvents. Two methods under development are wheat starch blasting and liquid carbon dioxide blasting. Wheat starch is water-soluble and is not considered a hazardous waste once the contaminants have been removed. Carbon dioxide evaporates after cleaning, and is currently being used for paint stripping. Dry machining, a process in which metal components are machined without oils or lubricants, is another no-clean al ternative that may be an option for certain metals and processes. Another non-solvent option is centrifugal cleaning. In this process, metal parts are centrifuged to remove oils and lubricants. This may be a viable option for parts that have a relatively low cleaning requirement.

\subsection{SOLVENTS USED TO CLEAN EOUIPMENT CONTAMINATED WITH RADIOACTIVE DUSTS}

A DOE-unique solvent use relates to cleaning equipment contaminated with radioactive dusts. These pieces of equipment are usually cleaned in glove boxes using CFC-113, because its low surface tension and high volatility provide good wetting and penetration for particle removal. CFC-113 is also used as a carrier for thin film applications, where the lubricant is placed in a CFC-113 solvent solution and applied to precision pieces such as bearings. After the CFC-113 evaporates, a stable oil film is left on the precision part. In addition, CFC-113 is used in cleaning plutonium and special electrical contacts. Extreme chemical stability, low toxicity, and inflammability make CFC-113 particularly valuable for these operations.

Because of the need to keep the amount of radioactively contaminated waste to a minimum, some of the alternatives available for general solvent uses do not lend themselves as well to nuclear activities. Aqueous solvents are capable of removing nuclear contamination, but aqueous processes often result in significant quantities of waste water that need to be treated and disposed of. One of the most promising technologies for replacing CFC-113 in cleaning radioactive materials is the use of supercritical fluids. These fluids are also highly stable chemically and have been demonstrated to 
dissolve many types of contaminants. Although further study is necessary, supercritical carbon dioxide may be a viable option for cleaning plutonium, and cleaning equipment contaminated with radioactive materials.

One non-solvent option that is currently being discussed is the use of centrifugal cleaning to remove oils from plutonium chips. 


\subsection{OVERVIEW OF CURRENT DOE ACTIVITIES TO PHASE OUT ODSS}

From preliminary information obtained by EH-23, it was determined that several DOE sites already have undertaken activities aimed at phasing out uses of ODSs. In contacts with representatives from these sites, it was discovered that some of these sites are investigating the issues related to ODS substitution but did not actually have phase-out plans in place. Other sites had not indicated to EH-23 that they were involved in ODS phase-out activities but that nonetheless have made significant progress toward diminishing ODS use $^{(a)}$. This is particularly true for solvent use. The material presented in this section is an overview of preliminary information gathered from contacts with personnel at specific DOE sites. This is not an exhaustive review of DOE facility activities.

In general, ODS phase-out activities at DOE facilities are not part of a specific ODS phase-out $\mathrm{plan}$, but rather are incorporated into other programs aimed at environmental compliance and waste minimization. Only a few sites had a single person or office overseeing ODS phase-out activities. The majority of DOE sites had personnel who use ODSs tasked with identifying specific replacement options for particular processes or equipment.

\subsection{FIRE SUPPRESSION}

Several sites have plans to phase out halon use in fire suppression systems and extinguishers. Pantex, the Continuous Electron Beam Accelerator Facility (CEBAF), and Ames Laboratory already have replaced halons in portable extinguishers. All these sites currently are storing the old halon extinguishers pending identification of a commercial recycle or recovery facility capable of processing the halon. CEBAF has replaced its portable Halon-1211 extinguishers with water-based extinguishers, while Rocky Flats is planning to retrofit to dry chemical extinguishers.

Pantex is currently in the process of replacing fixed fire suppression systems with sprinklers in all noncritical halon uses. For critical uses, substitutes are being sought. Ames is examining a range of options that

(a) A list of the DOE and contractor personnel contacted is attached as Appendix $B$. 
include sprinklers for the main facility and other options for the mobile lab. Dry chemicals are not an effective substitute because the mobile lab contains highly sensitive optical equipment that the chemicals would damage. $\mathrm{CO}_{2}$ is also not a fully viable option because it is temperature sensitive and poses potential health and safety problems.

Both CEBAF and Pantex are actively working with suppliers to determine the best approach to phase-out, including identifying viable alternatives.

\subsection{REFRIGERATION}

Pantex has installed refrigerant recyciling equipment for most of its refrigeration units, and has purchased two mobile air conditioning refrigerant recycling units. These are expected to achieve better than 95 percent recovery. All of Pantex's technicians have been certified to use the recycle equipment.

The Rocky Flats Plant Maintenance Facility Engineering Group has developed a proposal to replace Class I ODSs in refrigeration systems and to conserve and recycle Class II HCFCs throughout the plant site. A February 1991 document outlines proposed efforts to modify and retrofit existing plant equipment to allow CFC-11 and CFC-12 to be replaced by HCFC-123 and HCFC-124. Existing equipment will be disassembled and re-gasketed with a material that will not be affected by the alternate refrigerants. The proposal includes replacing existing "fusible plug" relief valves and "rupture disk" relief valves with spring-loaded relief valves to automatically reseat after an overpressure is relieved. When the existing relief valves are activated, the entire refrigerant charge is lost to the atmosphere, and a new pressure relief valve and refrigerant charge are required before the system can be put back into operation.

The Rocky Flats Engineering Group proposal includes purchasing refrigerant management systems that will minimize refrigerant losses during servicing and maintenance of refrigeration and air conditioning systems by allowing the repair person to remove and store the refrigerant, then reinstall it into the system after servicing or maintenance is complete. During this 
process the refrigerant management system cleans the refrigerant, removing oil, water, and acid contaminants.

\subsection{SOLVENTS}

A significant amount of work has been undertaken in the area of solvent replacement at DOE facilities. The Solvent Waste Stream group, composed of members of the Nuclear Weapons Complex (i.e., Y-12, Pinellas, Kansas City Plant, Sandia Albuquerque, Livermore, Los Alamos, Mound, and Pantex), has been in existence for about two years, but activities aimed at solvent replacement have been ongoing since 1987 . This group has a two-part agenda: (1) to replace ODS solvents in current DOE uses in the short term, and (2) to identify and develop non- or low-waste processes to replace current DOE uses in the long term.

Metal cleaning activities have been switched to aqueous processes at both Pantex and Rocky Flats. CEBAF is examining three options for spray CFC113 used in cleaning: isopropanol, methanol, and acetone. The facility is also examining the use of pressurized gas.

Rocky Flats also established a Chlorinated Solvent Elimination Task Team that is examining the potential for using slipercritical $\mathrm{CO}_{2}$ for cleaning plutonium as a replacement for methyl chloroform and carbon tetrachloride. The team is also examining the potential for dry machining, which eliminates the need to use solvents. Centrifugal cleaning may be a viable option for removing oil from plutonium chips. For duct cleaning activities, Rocky Flats is using De-solve-it, a non-Resource Conservation and Recovery Act solvent, in place of the carbon tetrachloride that was originally tagged for this activity. This is Rocky Flats' first glovebox usage of a substitute solvent.

Pantex currently is planning to use HCFC-141b for baths and wipes because it does not require any change in the existing equipment, and trials have shown that it works as well as the existing CFC used. Pantex is developing a database of commercial products currently being used at the facility. This database will contain information on the components of commercial products and help to identify CFCs that are part of a purchased product. 
Most solvent processes at Mound have already been modified away from CFC use. EPA requirements on using chlorinated solvents have affected Mound's solvent options. Mound is currently inventorying smaller CFC uses and developing purchase requirements to prevent the purchase of CFC-containing solvents in the future.

The Kansas City Plant is developing a Technical Task Plan for its Environmentally Conscious Manufacturing Project. This is aimed at identifying clean technologies for use with manufacturing processes to prevent CFC and VOC use and to limit waste generation and air emissions. Currently, the use of CFCs is dictated by the Nuclear Design Agency that operates from the Sandia, Lawrence Livermore, and Los Alamos National Laboratories, and by Mi1-specs that specifically call for CFCs to be used when testing to ensure that markings on weapons are permanent. The Kansas City Plant is developing a state-of-the-art precision cleaning facility to test new nonhazardous solvents.

At Oak Ridge, the $Y-12$ facility is replacing its metal cleaning solvents with ultrasonic cleaning and aqueous detergents. In this process, the equipment is dropped into a water and detergent solution. High frequency sound is put through this solution, which causes it to bubble on the equipment. This results in a mechanical as well as chemical cleaning. In situations where equipment needs to be wiped, high flash mineral spirits are being used. This solution, called Solvent 140 , is a straight chain hydrocarbon. Dipropylene-glycol-methylether is also used. These compounds are being studied to determine bonding and other characteristics. 


\subsection{CONCLUSIONS}

The use and consumption of CFCs and other ODSs will need to be phased out in a time frame consistent with the schedules mandated by the Clean Air Act, as amended, and the accelerated phase-out announced by President Bush. This report presents several potential substitutes and process changes that could reduce or replace ODSs in most DOE activities. However, because this information is based on broad categories of uses, individual DOE facilities should determine the types of substitutes and process changes that are most efficient for their specific activities.

Section 612 ("Safe Alternatives Policy") of the Clean Air Act, as amended, requires EPA to publish a list of safe alternatives as well as a list of prohibited substances deternined to pose a threat to human health or the environment. EPA plans to propose regulations implementing Section 612 by November 1992. Pending this action, considerable urcertainty exists for both manufacturers and potential users on which substances will qualify as safe alternatives for ODSs. Therefore, a cautious approach should be taken to making commitments for substitutes for ODSs at this time.

$\mathrm{Pl}$ ans concerning phase-out and safe alternatives should be established in a way that allows flexibility and meets the intent of the law. For example, HCFCS are potential substitutes for both solvent and refrigerant ODS uses. In the area of refrigeration and air conditioning, some HCFCS have the advantage of working as well as CFCs and also of being "drop in" replacements. Since several HCFCs also are currently targeted for phase-out, the issue of whether HCFCs should be used as substitutes is called into question. DOE facilities will need to make their own judgments on HCFC use. Issues to be considered in these judgments include the age of the equipment in which the HCFCs will be used and the costs for changing processes or identifying alternatives to the HCFCs at a later date. In addition, the timeline for phasing out HCFCs is expected to be accelerated. For some processes, it may be worthwhile to use HCFCs until other substitutes have been identified or until the equipment has reached the end of its useful life. In any case, HCFCs currently targeted for phase-out should be recognized as interim measures rather than as solutions to the ODS phase-out problem. 
In the area of fire protection, $\mathrm{plans}$ and procedures for using al ternative methods and chemicals should also be developed that meet particular facility requirements. In addition, plans and procedures for disposal or storage of the halon should be considered. The protection of certain critical assets may require using halons until suitable substitutes can be found for all fire suppression situations (e.g., exposure in occupied facilities). Decisions on the level and type of fire protection required will need to be made on a case-by-case basis.

A comprehensive, worldwide effort to eliminate ODSs is underway. The solutions are being developed at a rapid pace, and in most situations the technology can be transferred expeditiously. In some very specialized applications, widely accepted solutions have not yet been found. However, with the ongoing level of effort, alternatives should be developed in the near future for even the most stringent applications. 


\section{REFERENCES}

Air Conditioning and Refrigeration Institute (ARI). 1991. "Specifications for Fluorocarbon Refrigerants." ARI 700-88, Arlington, VA.

Clean Air Act Amendments of 1990. Public Law 101-549, 42 USC 7671.

Floden, John R., Capt. USAF. 1992. "Finding Fixes for Firefighting," The Military Engineer, Vol 84 No. 551, Auy 1992

Mei, V.C. and Chen, F.C. "Analys is of Non-CFC Automotive Air Conditioning," proceedings of International CFC and Halon Alternatives Conference, Dec 1991.

National Fire Protection Association (NFPA). 1989. "Halon-1301 Fire Extinguishing Systems." NFPA 12A Halon-1301 Fire Extinguishing Systems 1989 Edition. NFPA, Quincy, MA.

Settimo, Scott. 1991. "Fire Protection in the Critical Space: The Future of Halon-1301," The Construction Specifier, May 1991.

Society of Automotive Engineers (SAE). 1989. "Recycling and Servicing Procedures for the Containment of R-12." Book of Standards. SAE-1989, Warrendale, PA.

Society of Automotive Engineers (SAE). 1990. "Extraction and Recycle Equipment for Mobile Air Conditioning Systems." Book of Standards. SAE-1990, Warrendale, PA.

Society of Automotive Engineers (SAE). 1991. "Purity Standards for Recycled Refrigerants." Book of Standards. SAE-1991, Warrendale, PA.

United Nations Environment Programme (UNEP). 1991a. Halons Technical Options Committee. United Nations, New York.

United Nations Environment Programme (UNEP). 1989. Refrigeration, Air Conditioning, and Heat Pumps. United Nations, New York.

United Nations Environment Programme (UNEP). 1991b. Refrigeration, Air Conditioning, and Heat Pumps. United Nations, New York.

United Nations Environment Programme (UNEP). 1991c. Solvents, Coatings, and Adhesives Committee. United Nations, New York.

United Nations Environment Programme (UNEP). 1991d. Technology and Economic Assessment Panel. United Nations, New York.

U.S. Department of Defense (DOD). 1991. CFC Advisory Committee Report: Recommendations for Eliminating the Use of Ozone-Depleting Compounds in the Defense Sector. 
U.S. Department of Energy (DOE). 1989. "General Design Criteria." DOE Order 6430.1A.

U.S. Department of Energy (DOE). 1990. "Interim Position on Installation of New Halon-1301 Fixed Fire Suppression Systems and Halon Portable Fire Extinguishers." DOE, Safety and Quality Assurance, Washington, D.C.

U.S. Environmental Protection Agency (EPA). 1991a. Alternatives for CFC-113 and Methyl Chloroform in Metal Cleaning. EPA, Office of Toxic Substances, Washington, D.C.

U.S. Environmental Protection Agency (EPA). 1991b. Aqueous and Semi-aqueous Alternatives for CFC-113 and Methyl Chloroform Cleaning of Printed Circuit Board Assemblies. EPA, Office of Toxic Substances, Washington, D.C.

U.S. Environmental Protection Agency (EPA). 1990a. Aqueous and Terpene Cleaning, Interim Report. EPA, Office of Toxic Substances, Washington, D.C.

U.S. Environmental Protection Agency (EPA). 1991c. El iminating CFC-113 and Methyl Chloroform in Precision Cleaning Operations. EPA, Office of Toxic Substances, Washington, D.C.

U.S. Environmental Protection Agency (EPA). 1990b. Hydrofluorocarbons and Hydrochlorofluorocarbons Interim Report. EPA, Office of Toxic Substances, Washington, D.C. 


\section{APPENDIX A}

Possible Alternatives Being Considered For Review Under The Significant New Alternatives Policy (SNAP) Program 

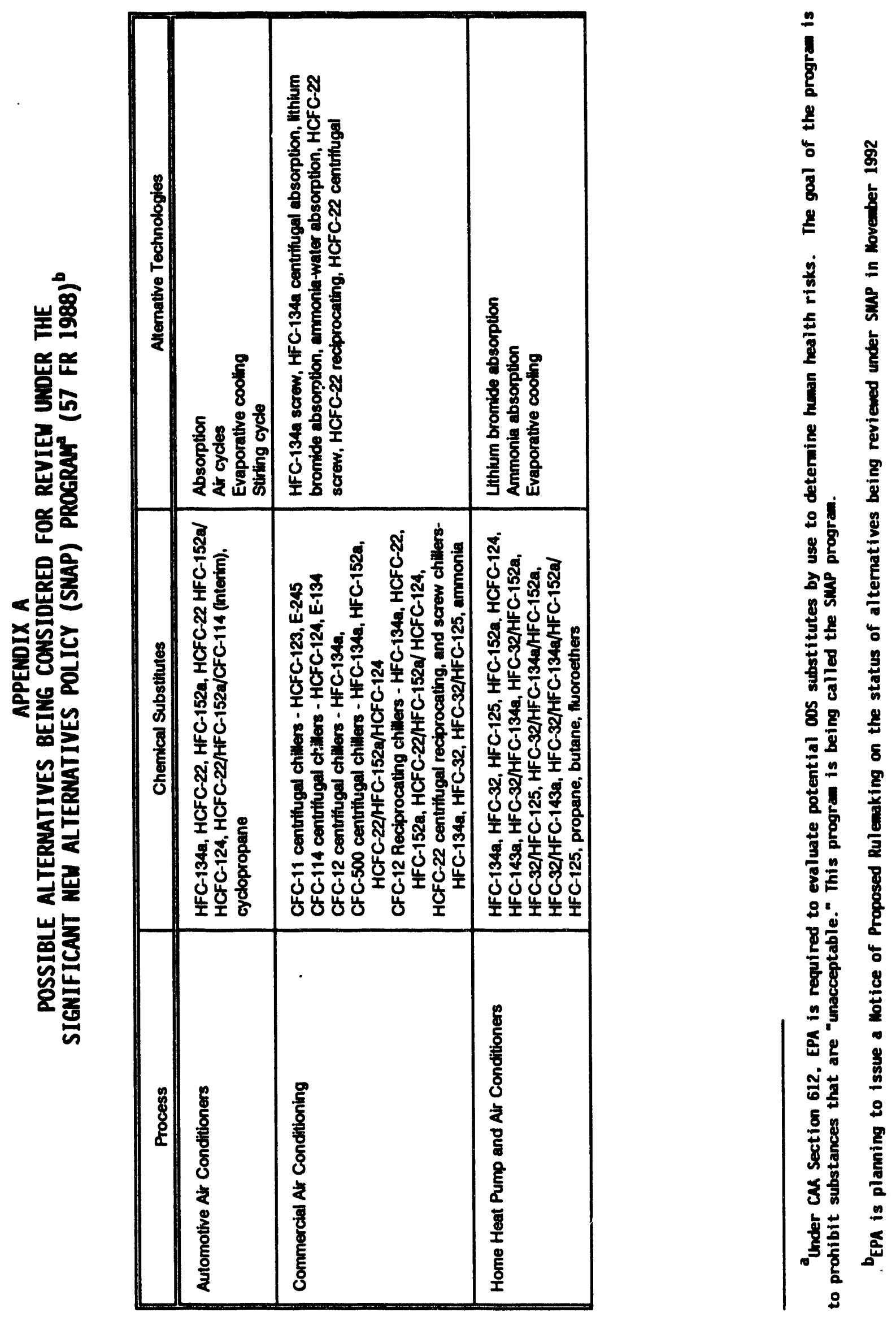

A. 1 


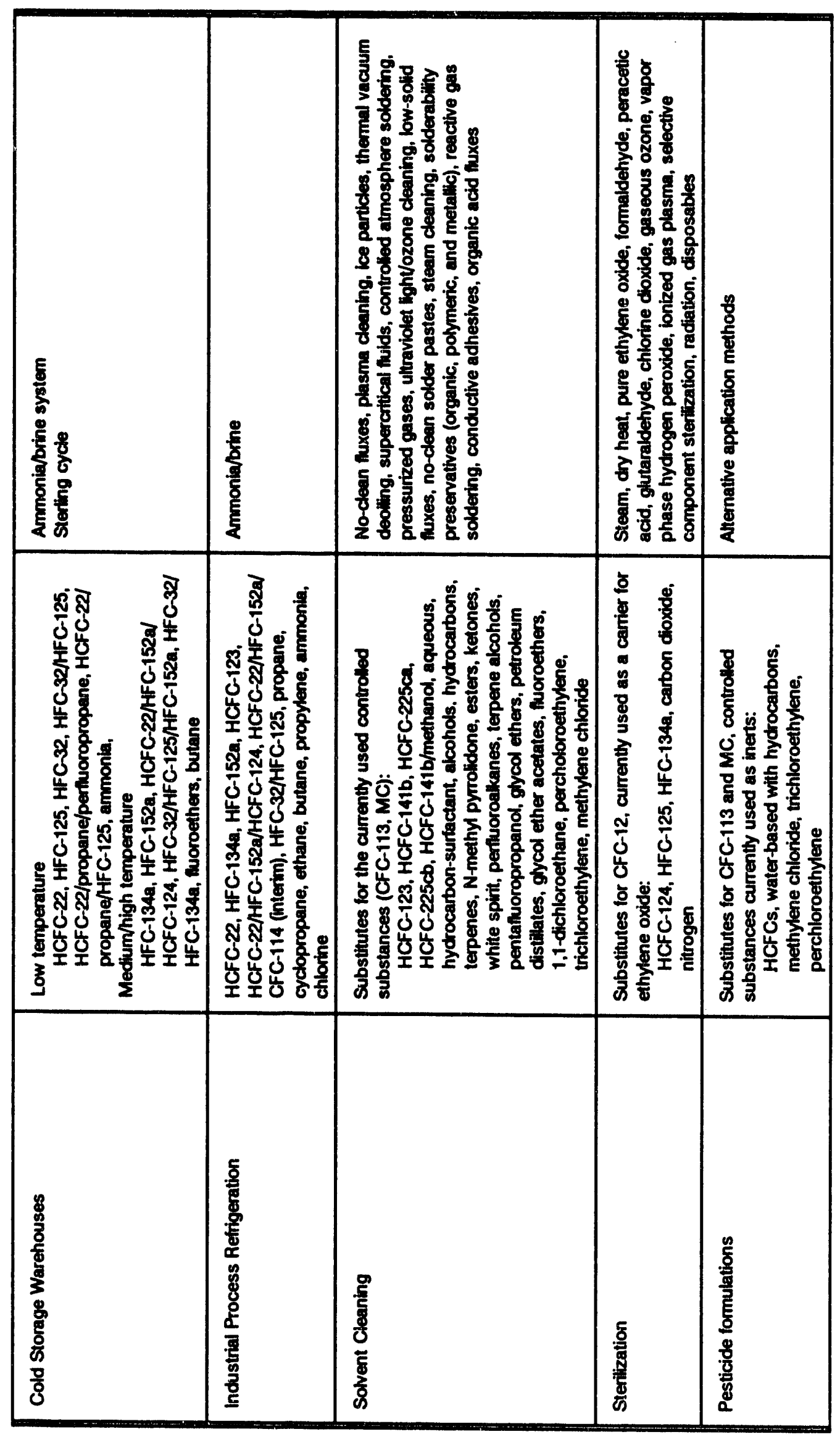




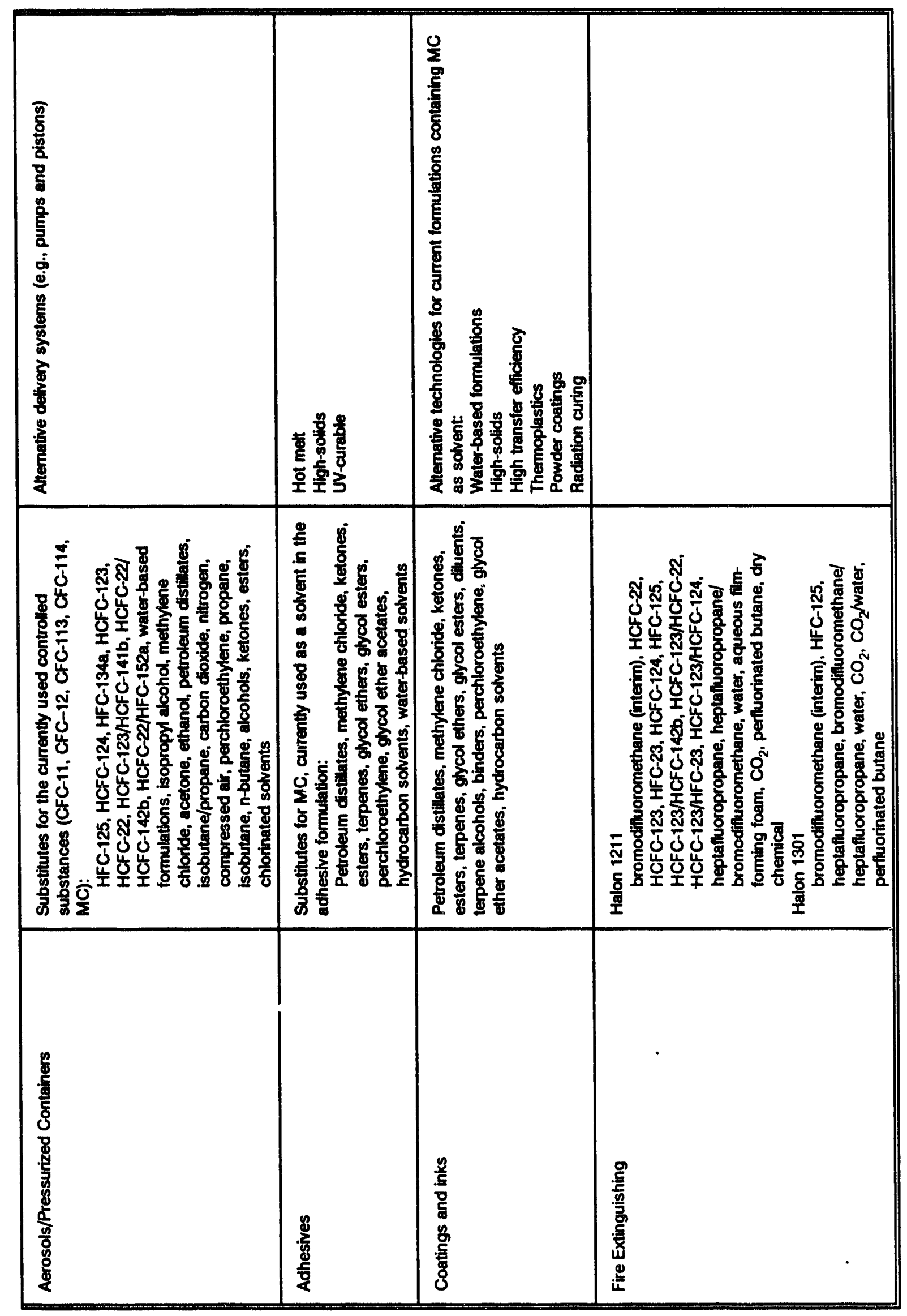

A. 3 
APPENDIX B

Selected Contacts 


\section{APPENDIX B}

\section{Selected Gontacts}

DOE Facilities

Continuous Electron Beam Accelerator Facility (CEBAF)

South Eastern Univ. Research Assoc.

Gina Dixon

804/249-7308

Pantex

Explosives Technology

Dr. Erwin Kohn

806/477-3473

Mound

EG\&G Mound, Inc.

Don Dicharo

513/865-3523

Ames Laboratory

Environment, Safety and Health Group

Lowell K. Mathison, Manager

515/294-2153

Kansas City Plant

Allied-Signal Aerospace

James Tira

816/997-2563

Gaseous Diffusion Plants

NE-33 Operations and Facility Reliability

Le0 Ewing

301/903-5442

Waste Reduction/Waste Minimization

Kathleen Hain

EM-50 Technology Development

301/903-7917

John Marchetti

DP-223 Production Facilities

301/903-5003
Pinellas

DOE Pinellas Area Office

Deborah Turner

813/541-8085

Rocky Flats Plant

EG\&G Rocky Flats, Inc.

Dr. Stephanie Hale

303/966-6077

DOE Richland Field Office

Steve Stites

509/372-0409

Savannah River Site

Westinghouse Facilities Group

John Harris

803/725-3465

Y-12

Martin Marietta Energy Systems, Inc. Lisa Thompson

615/576-4227
Dr. J. Kent Hancock

EM-35 Technical Support Division 301/903-7174

Jane Powers

EH-231 RCRAVCERCLA Division

202/586-7301 
Alternatives

Solvent Waste Stream

Sandia National Laboratory

Robyn Steifeld

505/844-5197

Dry, No-Clean Soldering

Sandia National Laboratory

Gay L. Dybwad

505/844 8236

Super Critical Fluids

EG\&G Rocky Flats, Inc.

Dr. Stephanie Hale

303/966-6077

CFC Substitutes

Westinghouse Savannah River Site

Larry Haney

803/725-3829

Cleaning Technology

CE-222 Waste Material Management

Division

Bruce Cranford

202/586-9496

Fire SuppressionlHalon

Dennis Kubicki

EH-31.3 Office of Occupational Safety $301 / 904-4794$
Database of Alternative Solvents Idaho National Engineering Laboratory Angela Chavez 208/526-7834

Air Quality Kansas City Plant

David Eggers

816/997-4045

Radionuclides

Westinghouse Savannah River Site John Harris 803/725-3465

Supercritical Fluid Los Alamos National Laboratory Dale Spall $505 / 667-4960$
Edward Connell

DP-621 Facilities Engineering Division 301/903-9831 


\section{APPENDIX B}

Selected Contacts

\section{General}

EPA Global Change Hotline 10am - 4pm EST 800/296-1996

US Air Force Programs

Major Tom Morehouse

AF Environmental Division 202/767-0275

ODS Alternatives

Charles Purcell

Pacific Northwest Laboratory

2C: $\sqrt{646-5206}$
DoD Programs

Mr. Bill Goins

DoD Environmental

703/693-8709

DOE General Phase-Out

Ted Koss

EH-232 Air, Water and Radiation Division 202/586-7964 


\section{DISTRIBUTION}

No. of

Copies

\section{OFFSITE}

12 DOE/Office of Scientific and Technical Information

T.H. KOSS

DOE/EH-23

1000 INDEPENDENCE AVE., S.W.

WASHINGTON, DC 20585

2 A R SEEPO

DOE/NE-60

1000 Independence Ave., S.W.

Washington, D.C. 20585

J AHLQUIST

DOE/EM425

12800 MIDDLEBROOK RD

GERMANTOWN, MD 20874

\section{H BARRETT}

DOE/DP-6.1

1000 Independence Ave., S.W.

Washington, D.C. 20585

R P BERUBE

DOE/EH-20

1000 Independence Ave, S.W.

Washington, D.C. 20585

\section{BRADLEY}

DOE/NE-33

1000 Independence Ave., S.W.

Washington, D.C. 20585

B CAMPBELL

DOE/CR-141

1000 Independence Ave., S.W.

Washington, D.C. 20585

\section{J L COALGATE}

DOE/EH-231

1000 Independence Ave., S.W.

Washington, D.C. 20585

R L DAILEY

DOE/EH-231

1000 Independence Ave., S.W.

Washington, D.C. 20585

G C DI CERBO

DOE/EH-231

1000 Independence Ave., S.W.

Washington, D.C. 20585

T C ELSASSER

DOE/EM-4

1000 Independence Ave., S.W.

Washington, D.C. 20585

\section{FAIROBENT}

DOE/EH-1

1000 Independence Ave., S.W.

Washington, D.C. 20585

M D FIORI

DOE/DR-1

1000 Independence Ave., S.W.

Washington, D.C. 20585

\section{J A FORD}

DOE/DP-63

19901 GERMANTOWN RD

GERMANTOWN, MD 20874

M W FREI

DOE/EM-34

1000 Independence Ave., S.W.

Washington, D.C. 20585

G GEARS

DOE/DP-62

19901 GERMANTOWN RD

GERMANTOWN, MD 20874

$S$ GOEL

DOE/ER-10

19901 GERMANTOWN RD

GERMANTOWN, MD 20874 
K E GOODWIN

DOE/DP-636

19901 GERMANTOWN RD

GERMANTOWN, MD 20874

J. VERNET

DOE/EP63

1000 INDEPENDENCE AVE. S.W.

WASHINGTON, DC 20585

D. KUBICKI

DOE/EH-31.3

1000 INDEPENDENCE AVE., S.W.

WASHINGTON, DC 20585

R. CAMERON

DOE ALBUQUERQUE

PO BOX 5400

ALBUQUERQUE, NM 87185-5400

E. CONNELL

DOE/DP-621

1000 INDEPENDENCE AVE, S.W.

WASHINGTON, DC 20585

D. SPALL

LOS ALAMOS NATIONAL LAB

PO BOX 1663

LOS ALAMOS, NM 87545

R D HAHN

DOE/DP-64

19901 GERMANTOWN RD

GERMANTOWN, MD 20874

L H HARMON

DOE/EM-53

1000 Independence Ave., S.W.

Washington, D.C. 20585

N L JOHNSON

DOE/FE-4

1000 Independence Ave., S.W.

Washington, D.C. 20585

M A KILPATRCIK

DOE/EH-24

1000 Independence Ave., S.W.

Washington, D.C. 20585
A C LAWRENCE

DOE/EH-232

1000 Independence Ave., S.W.

Washington, D.C. 20585

2 E D SHOLLENBERGER

DOE/NE-60

1000 Independence Ave., S.W.

Washington, D.C. 20585

J V ANTIZZO

DOE/EM-361

12800 MIDDLEBROOK RD

GERMANTOWN, MD 20874

J J BASCIETTO

DOE/EH-231

1000 Independence Ave., S.W.

Washington, D.C. 20585

W BIXBY

DOE/EM-40

1000 Independence Ave., S.W.

Washington, D.C. 20585

\section{R A BRADLEY}

DOE/S-1

1000 Independence Ave., S.W.

Washington, D.C. 20585

J CARNEY

DOE/ER-922

19901 GERMANTOWN RD

GERMANTOWN, MD 20874

J A COLEMAN

DOE/EM35

12800 MIDDLEBROOK RD

GERMANTOWN, MD 20874

W H DELAPLANE

DOE/FE-421

1000 Independence Ave., S.W.

Washington, D.C. 20585

J DISBROW

DOE/EI-531

1000 Independence Ave., S.W.

Washington, D.C. 20585 
R W ENGLEHART

DOE/NP-2

1000 Independence Ave., S.W.

Washington, D.C. 20585

J K FARLEY

DOE/ER-8.2

19901 GERMANTOWN RD

GERMANDTOWN, MD 20874

J FISHER

DOE/CP-40

1000 Independence Ave., S.W.

Washington, D.C. 20585

W B FORTUNE

DOE/EH-231

1000 Independence Ave., S.W.

Washington, D.C. 20585

Y M GARBE

DOE/EH-5

1000 Independence Ave., S.W.

Washington, D.C. 20585

M A GILBERTSON

DOE/EH-5

1000 Independence Ave., S.W.

Washington, D.C. 20585

O GOKTEPE

DOE/ER-22

19901 GERMANTOWN RD

GERMANTOWN, MD 20874

B A GRIMM

DOE/EH-20

1000 Independence Ave., S.W.

Washington, D.C. 20585

C G HALSTED

DOE/DP-27

19901 GERMANTOWN RD

GERMANTOWN, MD 20874

D F HOEL

DOE/NP-53

1000 Independence Ave., S.W.

Washington, D.C. 20585
R JONES

DOR/EH-41

19901 GERMANTOWN RD

GERMANTOWN, MD 20874

A E KNIGHT

DOE/CP-20

1000 Independence Ave., S.W.

Washington, D.C. 20585

O J LAWRENCE

DOE/CE-64

1000 Independence Ave., S.W.

Washington, D.C. 20585

R L ADELMAN

WDC

1000 Independence Ave., S.W.

Washington, D.C. 20585

L H BANICKI

EH-24

1000 Independence Ave., S.W.

Washington, D.C. 20585

J E BAUBLITZ

EM-40

1000 Independence Ave., S.W.

Washington, D.C. 20585

C M BORGSTROM

EH-25

1000 Independence Ave., S.W.

Washington, D.C. 20585

\section{S J BROCOUM}

RW-22

1000 Independence Ave., S.W.

Washington, D.C. 20585

A CLEARY

EH-1

1000 Independence Ave., S.W.

Washington, D.C. 20585

S P COWAN

EM-30

1200 MIDDLEBROOK RD

GERMANTOWN, MD 20874 
W DENNISON

GC-11

1000 Independence Ave., S.W.

Washington, D.C. 20585

C W EBBECKE

NP-20

1000 Independence Ave., S.W.

Washington, D.C. 20585

A E EVANS

ER-13

1000 Independence Ave., S.W.

Washington, D.C. 20585

JJ FIORE

EM-42

12800 MIDDLEBROOK RD

GERMANTOWN, MD 20874

J E FITZGERALD

EH-30

1000 Independence Ave., S.W.

Washington, D.C. 20585

C S FRANK

EM-50

12800 MIDDLEBROOK RD

GERMANTOWN, MD 20874

H K GARSON

NP-1

1000 Independence Ave., S.W.

Washington, D.C. 20585

R G GISCH

NE-60

NC-2 BLDG

2521 JEFFERSON DAVIS HIGHWAY

ARLINGTON, VA 22202

D N GOODWIN

ER-20.1

19901 GERMANTOWN RD

GERMANTOWN, MD 20874

P D GRIMM

EM-2

1000 Independence Ave., S.W.

Washington, D.C. 20585

\section{J K HANCOCK}

EM-352

12800 MIDDLEBROOK RD

GERMANTOWN, MD 20874

D S JEWETT

FE-222

1000 Independence Ave., S.W.

Washington, D.C. 20585

A G JOSEPH

ER-40

1000 Independence Ave., S.W.

Washington, D.C. 20585

\section{F A KOOMANOFF}

ER-10

19901 GERMATOWN RD

GERMANTOWN, MD 20874

L LICHTMAN

EH-25

1000 Independence Ave., S.W.

Washington, D.C. 20585

R G LIGHTNER

EM-45

19901 GERMANTOWN R ?

GERMANTOWN, MD $2 \Gamma 74$

J E LYTLE

EM-30

12800 MIDDLEBROOK RD

GERMANTOWN, MD 20874

M J MATARRESE

FE-64

1000 Independence Ave., S.W.

Washington, D.C. 20585

R H MORRE

EI-23.1

1000 Independence Ave., S.W.

Washington, D.C. 20585

L NAKATA

EH-231

1000 Independence Ave., S.W.

Washington, D.C. 20585 


\section{G J PARKER}

RW-333

1000 Independence Ave., S.W.

Washington, D.C. 20585

H T PETERSON JR

EH-232

1000 Independence Ave., S.W.

Washington, D.C. 20585

T PFLAUM

DP-9

1000 Independence Ave., S.W.

Washington, D.C. 20585

D R RHOADES

DP-65

19901 GERMANTOWN RD

GERMANTOWN, MD 20874

P J RITZCOVAN

NP-52

1000 Independence Ave., S.W.

Washington, D.C. 20585

\section{K SCHMIDT}

EH-231

1000 Independence Ave., S.W.

Washington, D.C. 20585

R K SHARMA

NE-47

1000 Independence Ave., S.W.

Washington, D.C. 20585

E Livingston

EM-5

1000 Independence Ave., S.W.

Washington, D.C. 20585

\section{S A Mann}

EM-44

1000 Independence Ave., S.W.

Washington, D.C. 20585

J B McGrory

ER-23

19901 Germantown Road

Germantown, MD 20874
D O Moses

PE-70

1000 Independence Ave., S.W.

Washington, DC 20585

W S Osburn, Jr.

ER-73

19901 Germantown Road

Germantown, MD 20874

R Pelletier

EH-23

1000 Independence Ave., S.W.

Washington, DC 20585

H J Pettengill

EH-40

19901 Germantown Road

Germantown, MD 20874

J POWERS

EH-231

1000 Independence Ave., S.W.

Washington, DC 20585

J E RHODERICK

EM-351

12800 MIDDLEBROOK ROAD

GERMANTOWN, MD 20874

S H ROSSI

ER-53

19901 GERMANTOWN ROAD

GERMANTOWN, MD 20874

J C SCHUMANN

EM-11

19901 GERMANTOWN ROAD

GERMANTOWN, MD 20874

D D SHELOR

RW-30

1000 INDEPENDENCE AVE, S.W.

WASHINGTON, DC 20585

R J LYNCH

DP-643

19901 GERMANTOWN ROAD

GERMANTOWN, MD 20874 
J M MARCHETTI

DP-644

19901 GERMANTOWN ROAD

GERMANTOWN, MD 20874

\section{S MILLER}

GC-11

1000 INDEPENDENCE AVE., S.W.

WASHINGTON, DC 20585

N NAEGELE

EH-23

1000 INDEPENDENCE AVE, S.W.

WASHINGTON, DC 20585

C A OSTROWSKI

EG-232

1000 INDEPENDENCE AVE., S.W.

WASHINGTON, DC 20585

F G PETERS

RW-2

1000 INDEPENDENCE AVE., S.W.

WASHINGTON, DC 20585

M E PETTS

EC-231

1000 INDEPENDENCE AVE., S.W.

WASHINGTON, DC 20585

E P REGNIER

EH-232

1000 INDEPENDENCE AVE, 3.W.

WASHINGTON, DC 20585

S D RICHARDSON

DP-60

1000 INDEPENDENCE AVE., S.W.

WASHINGTON, DC 20585

F B RUSSO

EH-24

1000 INDEPENDENCE AVE., S.W.

WASHINGTON, DC 20585

R S SCOTT

EM-20

1000 INDEPENDENCE AVE., S.W.

WASHINGTON, DC 20585
A SMITH

BPA

1000 INDEPENDENCE AVE., S.W.

WASHINGTON, DC 20585

M T STAHR

EM-441

12800 MIDDLEBROOK ROAD

GERMANTOWN, MD 20874

K I TAIMI

EG-22

1000 INDEPENDENCE AVE., S.W.

WASHINGTON, DC 20585

T T TRACESKI

EH-231

1000 INDEPENDENCE AVE., S.W.

WASHINGTON, DC 20585

D M VALENTINE

RW-332

1000 INDEPENDENCE AVE., S.W.

WASHINGTON, DC 20,585

B R WHITEHEAD

EG-231

1000 INDEPENDENCE AVE., S.W.

WASHINGTON, DC 20585

R W WOOD

ER-74

19901 GERMANTOWN ROAD

GERMANTOWN, MD 20874

L E STEVENS

EM-331

1000 INDEPENDENCE AVE., S.W.

WASHINGTON, DC 20585

C A THOMPSON

NE-43

1000 INDEPENDENCE AVE., S.W.

WASHINGTON, DC 20585

J C TSENG

EM-36

1000 IMDEPENDENCE AVE., S.W. WASHINGTON, DC 20585 
A WALLO, III

EH-232

1000 INDEPENDENCE AVE., S.W.

WASHINGTON, DC 20585

W E WISENBAKER

EM-43

12800 MIDDLEBROOK ROAD

GERMANTOWN, MD 20874

J G YATES

ER-42

1000 INDEPENDENCE AVE., S.W.

WASHINGTON, DC 20585

D F SWINK

FE-4

1000 INDEPENDENCE AVE., S.W.

WASHINGTON, DC 20585

C J THOMPSON

EH-231

1000 INDEPENDENCE AVE., S.W.

WASHINGTON, DC 20585

F A TURI

EM-33

1000 INDEPENDENCE AVE., S.W.

WASHINGTON, DC 20585

L A WEINER

EH-5

1000 INDEPENDENCE AVE., S.W.

WASHINGTON, DC 20585

W WOLFF

DP-633

19901 GERMANTOWN ROAD

GERMANTOWN, MD 20874

5 G C BOWMAN

US DOE-IDAHO

785 DOE PLACE

IDAHO FALLS, ID 83402

5 N S DIENES

US DOE-ALBUQUERQUE

PO BOX 5400

ALBUQUERQUE, NM 87185-5400
5 R R NELSON

US DOE-OAK RIDGE

PO BOX 2001

OAK RIDGE, TN 27831

5 B W CHURCH

US DOE-NEVADA

PO BOX 98518

LAS VEGAS, NV $89193-8518$

5 J T DAVIS

US DOE-SAN FRANCISCO

1333 BROADWAY

OAKLAND, CA 94612

2 M C KELLER

US DOE- PITTSBURGH

PO BOX 10940

PITTSBURGH, PA 15236-0940

2 J GANZ

US DOE-MORGANTOWN

PO BOX 880

MORGANTOWN, WV 26507-0880

2 W R MILLER

US DOE-MORGANTOWN

PO BOX 880

MORGANTOWN, WV 26507-0880

2 L C GOIDELL

US DOE-SAVANNAH RIVER

PO BOX A

AIKEN, SC 29808

2 A B GOULD

US DOE-SAVANNAH RIVER

PO BOX A

AIKEN, SC 29808

2 T F HEENAN

US DOE-OAK RIDGE

PO BOX 2001

OAK RIDGE, TN 37831

2 H W HIBBITTS

US DOE-OAK RIDGE

PO BOX 2001

OAK RIDGE, TN 37831 
2 L C SJOSTRUM

US DOE-SAVANNAH RIVER

PO BOX A

AIKEN, SC 29808

2 G W JOHNSON

US DOE-PINELLAS AO

PO BOX 2900

LARGO, FL 34649

2 P J GROSS

US DOE-OAK RIDGE

PO BOX 2001

OAK RIDGE, TN 37831

2 J A MORLEY

US DOE-DAYTON AO

PO BOX 66

MLAMISBURG, OH 45343-0066

2 B R FRITZ

US DOE-CHICAGO

9800 S CASS AVE

ARGONNE, IL 60439

2 R C SLEEMAN

US DOE-OAK RIDGE

PO BOX 2001

OAK RIDGE, TN 37831

2 J P KENNDEY

US DOE-CHICAGO

9800 S CASS AVE

ARGONNE, IL 60439

2 E W BEAN

DOE-KANSAS CITY

PO BOX 412525

KANSAS CITY, MO 64141-0202

2 P M RAMEY

US DOE-AMARILLO

PO BOX 30030

AMARILLO, TX 79120-0030

2 D MILES

US DOE NP \& OS RESERVES

907 N POPULAR

CASPER, WY 82601
2 D L KRENZ

US DOE ALBUQUERQUE

PO BOX 5400

ALBUQUERQUE, NM 87185-5400

2 D R ELLE

US DOE NEVADA

PO BOX 98515

LAS VAGAS, NV 89193-8518

2 J K HARTMAN

US DOE SAN FRANCISCO

1333 BROADWAY

OAKL.AND, CA 94612

2 R WALDMAN

US DOE ALASKA POWER ADMIN 2770 SHERWOOD LANE \#2B

JUNEAU, AK 99801

2 M W SMITH

US DOE SPRO

900 COMMERCE ROAD E

NEW ORLEANS, LA 70123

2 W L JAMISON

US DOE WAPA

PO BOX 3402

GOLDEN, CO 80401

2 W N SATO

US DOE IDAHO

785 DOE PLACE

IDAHO FALLS, ID 83402

2 R F SENA

ENVIRON RESTORATION

US DOE ALBUQUERQUE

PO BOX 5400

ALBUQUERQUE, NM 87185-5400

2 J N FIORE

US DOE NEVADA

PO BOX 98518

LAS VEGAS, NV 89193-8518

2 J JUETTEN

US DOE SAN FRANCISCO

1333 BROADWAY

OAKLAND, CA 94612 
2 L E LITTLE

US DOE RICHLAND

PO BOX 550

RICHLAND, WA 99352

2 J C KILLEN

US DOE NAVAL PETRO RES

PO BOX 11

TUPMAN, CA 93276

2 J L BELLOWS

US DOE LOS ALAMOS

528 35TH STREET

LOS ALAMOS, NM 87544

2 M L MATTHEWS, JR

US DOE AL UMTRA

PO BOX 5400

ALBUQUERQUE, NM 87115

2 T A VAETH

ROCKY FLATS AO

PO BOX 928

GOLDEN, CO 80402-0928

2 A B CRAWLEY

US DOE BARTLESVILLE PO

PO BOX 1398

BARTLESVILLE, OK 74005

P J ROWLAND

PO BOX 191

WEST VALLEY, NY 14171

J GASPER

ARGONNE NAT'L LAB

370 L'ENFANT PRM SW

WASHINGTON, DC 20024

L SCHULTZ

ENERGETICS

7164 GATEWAY DRIVE

COLUMBIA, MD 21046-2101

REMEDIAL ACTION PIC MARTIN MARIETTA ENERGY SY PO BOX 2003

OAK RIDGE, TN 37831
L K PRICE

EW-93

PO BOX 2001

OAK RIDGE, TN 37831

G WESTERBACK

PO BOX 398705

CINCINNATI, OH $45239-8705$

J HUNZE

US DOE CHICAGO

9800 SOUTH CASS AVE

ARGONNE, IL 60439

J MARTIN

US DOE MORGANTOWN

PO BOX 880

MORGANTOWN, WV 26507-0880

F BAES

OAK RIDGE NAT'L LAB

PO BOX 2008

OAK RIDGE, TN 37831

L RADCLIFF

US DOE OAK RIDGE

PO BOX 2001

OAK RIDGE, TN 37831

G W WESTERBECK

US DOE FERNALD

PO BOX 398705

CINCINNCTI, OH $45239-8705$

T C WESSON

BARTLESVILLE PO

PO BOX 1398

BARTLESVILLE, OK 74005

J B LLOYD

SOUTHEASTERN PA

SAMUEL ELBERT BLDG

ELBERTON, GA 30635

HAZWRAP

K-1210

MARTIN MARIETTA ENERGY SY

PO BOX 2003

OAK RIDGE, TN 37831 
R E TILLER

FERNAL FO

PO BOX 398705

CINCINNATI, OH $\quad 45239-8705$

J C HAUGEN

US DOE CHICAGO

9800 SOUTH CASS AVE

ARGONNE, IL 60439

D L HAYES

US DOE SOUTHWESTERN PA

PO BOX 1619

TULSA, OK 74105

F LOCKHART

ROCKY FLATS AO

PO BOX 928

GOLDEN, CO 80401-0928

J BAKER

NREL AO

1617 COLE BUILDING

GOLDEN, CO 80401

N BROWN

SSC PO

2550 BECKLEYMEADE \#1020

DALLAS, TX 75237

T E LUKOW

ROCKY FLATS AO

PO BOX 928

GOLDEN, CO 80402-0928

$M$ VAN DERPUY

ROCKY FLATS AO

PO BOX 928

GOLDEN, CO 80402-0928

NAT LOW-LEVEL WASTE

EG\&G IDAHO INC

PO BOX 1625

IDAHO FALLS, ID 83402

P HINMAN

US DOE IDAHO

785 DOE PLACE

IDAHO FALLS, ID 83402
A R CHERNOFF, JR

US DOE UMPTRA PO

PO BOX 5400

ALBUQUERQUE, NM 87185-5400

A E HUNT

WIPP PO

PO BOX 3090

CARLSBAD, NM 88221

S A MELLINGTON

US DOE NEVADA

PO BOX 98518

LAS VEGAS, NV 89193-8518

J CULLEN

US DOE SAN FRANCISCO

1333 BROADWAY

OAKLAND, WA 94612

R GUERCIA

US DOE RICHLAND

PO BOX 550

RICHLAND, WA 99352

J L LYLE

US DOE IDAHO

785 DOE PLACE

IDAHO FALLS, ID 83402

D J COOK

CENT TRAINING ACAD

PO BOX 5400

ALBUQUERQUE, NM 87185-5400

J A MEWHINNEY

WIPP PO

PO BOX 3090

CARLSBAD, NM 88221

J D ROSS

US DOE NEVADA

PO BOX 98518

LAS VEGAS, NV 89193-8518

B HOLT

US DOE RICHLAND

PO BOX 550

RICHLAND, WA 99352 
K CARLSON

KIRTLAND AO

PO BOX 5400

ALBUQUERQUE, NM 87185-5400

C L SODEN

HEALTH PROTECTION

PO BOX 5400

ALBUQUERQUE, NM 87185-5400

F K GRASSMEIR

OCB

PO BOX 98608

LAS VEGAS, NV 89021

E BALLARD

US DOE SAN FRANCISCO

1333 BREADWAY

OAKLAND, CA 94612

R D IZATT

US DOE RICHLAND

PO BOX 550

RICHLAND, WA 99352

CHRIS ANDERSON

MAIL STOP 1146

DOE-IDAHO

785 DOE PLACE

IDAHO FALLS, ID 83402

DON ELLISON

PO BOX 11

ELK HILLS PETROLEUM RESERVES

TUPMAN, CA 93276

ELIAS GEORGE

PITTSBURGH ENERGY TECHNOLOGY

CENTER

PO BOX 10940

PITTSBURGH, PA 15236

SHIV GOEL

DOE-ALBUQUERQUE

PO BOX 5400

ALBUQUERQUE, NM 87115

MAL HUMPHREYS, SE 311

PO BOX 2001

OAK RIDGE, TN 37831
GARY LEVAGNINO

1333 BROADWAY

OAKLAND, CA 94612

BEHRAM SHROFF

DOE-FERNALD OFFICE

PO BOX 398705

CINCINNATI, OH $\quad 45239.8705$

DEBBY TURNER

US DOE

PO BOX 2900

LARGO, FL 34649

STUART ALTMAN

DP-161

19901 GERMANTOWN ROAD

GERMANTOWN, MD 20874

STEVE BUCKLEY

EM-20

1000 INDEPENDENCE AVE., S.W.

WASHINGTON, DC 20585

STEVE FERGUSON

GC-11

1000 INDEPENDENCE AVE., S.W.

WASHINGTON, DC 20585

REMI LANGUM

EM-431

19901 GERMANTWON ROAD

GERMANTOWN, MD 20875

RICHARD W. EARL

AD-14

1000 INDEPENDENCE AVE., S.W.

WASHINGTON, DC 20585

GENE FLEMING

AD-21

1000 INDEPENDENCE AVE., S.W.

WASHINGTON, DC 20585

EDWARD TUTTLE

AD-15

1000 INDEPENDENCE AVE., S.W.

WÄSHINGTON, DC 20585 
VINCENT BROOKS

AD-643

1000 INDEPENDENCE AVE., S.W.

WASHINGTON, DC 20585

DONALD FRIZZELL

AD-643

19901 GERMANTOWN ROAD

GERMANTOWN, MD 20874

JAMES TIRA

ALLIED-SIGNAL INC.

2000 E 95TH STREET

PO BOX 419159; DEPT 837-2C43

KANSAS CITY, MO 64141-6159

GINA DIXON, SEURA

12000 JEFFERSON AVE B12

NEWPORT NEWS, VA 23606

DR ERWIN KOHN

PANTEX

MASON \& HANGER

EXPLOSIVES TECHNOLOGY DIVISION

PO BOX 30020

AMARILLO, TX 79177

DON DICHARO

MOUND APPLIED TECHNOLOGIES

PO BOX 3000 BLDG 88

MIAMISBURG, OG $45343-3000$

LOWELL K MATHISON

AMES LAB

115 SPEDDING HALL

AMES, IA 50011

GASEOUS DIFFUSION PLANTS

LEE EWING

DOE, NE-33

GERMANTOWN, MD 20874

STEVE STITES

DOE

PO BOX 550

RICHLAND, WA 99352

JOHN HARRIS

SAVANNAH RIVER SITE

BLDG 742-A

WESTINGHOUSE - SAVANNAH RIVER

AIKEN, SC 29802
LISA THOMPSON

Y-12

MARTIN MARIETTA

PO BOX 2009

OAK RIDGE, TN 37831-8095

KATHLEEN HAIN

DOE-EM 55

1000 INDEPENDENCE AVE., S.W.

WASHINGTON, DC 20585

JOHN MARCHETTI

10910 FRUITWOOD DRIVE

BOWIE, MD 20720

DR J KENT HANCOCK

DOE EM-35

WASTE OPERATIONS

1000 INDEPENDENCE AVE., S.W.

WASHINGTON, DC 20585

JANE POWERS

DOE EH-231

RCRA/CERCLA DIVISION

1000 INDEPENDENCE AVE., S.W.

WASHINGTON, DC 20585

DR. STEPHANIE HALE

RFP -EG\&G RF INC.

BOC 464 BUILDING 779

GOLDEN, CO 80402-0464

\section{LARRY HANEY}

PO BOX 616 BLDG 742-A

WESTINGHOUSE-SAVANNAH RIVER

AIKEN, SC 29802

DAVID EGGERS

DEPT 922, SC-8

PO BOX 419159

ALLIED SIGNAL AEROSPACE

KANSAS CITY, MO 64141

DALE SPELL

LOS ALAMOS NATIONAL LAB

CLS-1 G-740

PO BOX 1663

LA NEW MEXICO 87545 
BRUCE CRANFORD

DOE CE 222

WASTE MATERIAL MANAGEMENT

DIVISION

1000 INDEPENDENCE AVE., S.W.

WASHINGTON, DC 20585

ANGELA CHAVEZ

EG\&G IDAHO

IDAHO FALLS, ID 83415-2208

MAJOR TOM MOREHOUSE

BOLLING AIR FORCE BASE

BLDG 516

HQ-USAF/CEVV

WASHINGTON, DC 20332-5001

WILLIAM GOINS

400 ARMY \& NAVY DRIVE

SUITE 206

ARLINGTON, VA 22202-2884

J WILLIAMS

BROOKHAVEN NATIONAL

LABORATORY

BUILDING 129B

UPTON, NY 11973

GAY L DYBWAD

SANDIA NATIONAL LAB

PO BOX 5800

OR6 6611

ALBUQUERQUE, NM 87185

ROBYN STEIFELD

SANDIA NATIONAL LAB

PO BOX 5800

OR6 6611

ALBUQUERQUE, NM 87185

\section{ONSITE}

DOE Richland Operations Office

D. SEGNA

Pacific Northwest Laboratory

5 C.W. PURCELL

42 K.B. MILLER

J.R. FRIEDMAN

R.D. RAPOPORT

D.R. CONOVER

P.L. HENDRICKSON

J.D. LONGSTRETH

M.K. COMER

W.E. KENNEDY

J.S. SHORETT

R.V. NORASKI

G.R. BILYARD

C.A. GEFFEN 

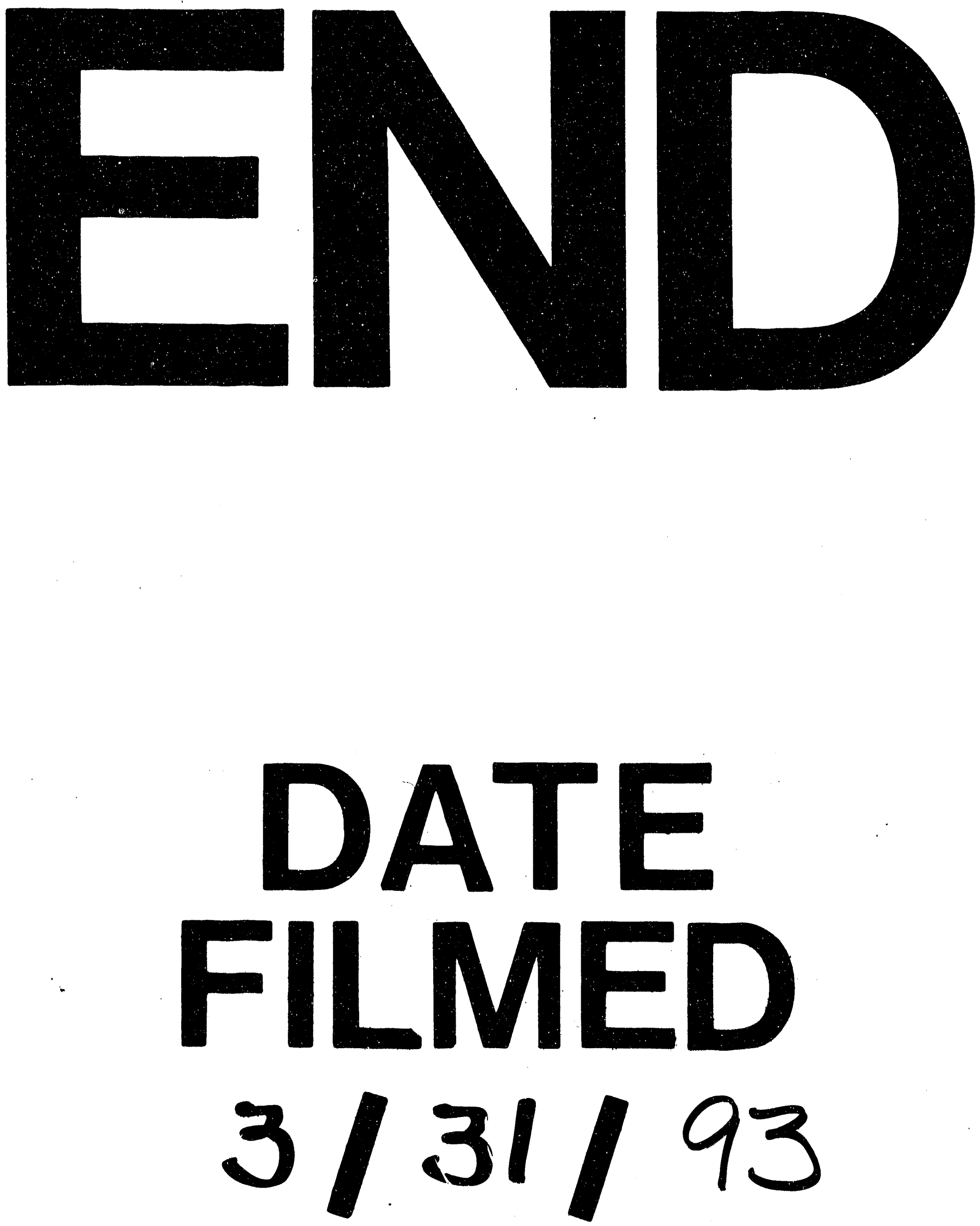


\section{.}

